\title{
Zinc-Based Nanomaterials for Diagnosis and Management of Plant Diseases: Ecological Safety and Future Prospects
}

\author{
Anu Kalia ${ }^{1, *(\mathbb{D})}$, Kamel A. Abd-Elsalam ${ }^{2}$ (1) and Kamil Kuca ${ }^{3, *(\mathbb{C})}$ \\ 1 Electron Microscopy and Nanoscience Laboratory, Department of Soil Science, College of Agriculture, \\ Punjab Agricultural University, Ludhiana 141004, Punjab, India \\ 2 Agricultural Research Center (ARC), Plant Pathology Research Institute, Giza 12619, Egypt; \\ kamelabdelsalam@gmail.com \\ 3 Department of Chemistry, Faculty of Science, University of Hradec Králové, \\ 50003 Hradec Králové, Czech Republic \\ * Correspondence: kaliaanu@pau.edu (A.K.); kamil.kuca@uhk.cz (K.K.); \\ Tel.: +91-2401960 (A.K.); +420-603-289-166 (K.K.)
}

Received: 22 September 2020; Accepted: 10 October 2020; Published: 13 October 2020

\begin{abstract}
A facet of nanorenaissance in plant pathology hailed the research on the development and application of nanoformulations or nanoproducts for the effective management of phytopathogens deterring the growth and yield of plants and thus the overall crop productivity. Zinc nanomaterials represent a versatile class of nanoproducts and nanoenabled devices as these nanomaterials can be synthesized in quantum amounts through economically affordable processes/approaches. Further, these nanomaterials exhibit potential targeted antimicrobial properties and low to negligible phytotoxicity activities that well-qualify them to be applied directly or in a deviant manner to accomplish significant antibacterial, antimycotic, antiviral, and antitoxigenic activities against diverse phytopathogens causing plant diseases. The photo-catalytic, fluorescent, and electron generating aspects associated with zinc nanomaterials have been utilized for the development of sensor systems (optical and electrochemical biosensors), enabling quick, early, sensitive, and on-field assessment or quantification of the test phytopathogen. However, the proficient use of Zn-derived nanomaterials in the management of plant pathogenic diseases as nanopesticides and on-field sensor system demands that the associated eco- and biosafety concerns should be well discerned and effectively sorted beforehand. Current and possible utilization of zinc-based nanostructures in plant disease diagnosis and management and their safety in the agroecosystem is highlighted.
\end{abstract}

Keywords: ecotoxicity; nanomaterial; nanosensors; phytopathogens; zinc

\section{Introduction}

Microbial pathogenic diseases of crop plants account for substantial annual loss (in the relative manner depicted as a percentage), approximately $16-40 \%$, of production tonnage [1]. The bacterial and fungal pathogens of various crops exhibit enormous yield and productivity losses during production and postharvest storage as well as during transportation of the crop produce [2]. To safeguard the crop from crop health and yield deterring pathogens, pesticides- organic or inorganic compounds, or their composites have been used by agriculturists or farmers. Among the diverse pesticidal agents utilized to curb weeds and plant pathogens, zinc and copper formulations have emerged as the best performers. 


\subsection{Use of Zinc Element as a Pesticide}

Zinc alone or in combination with copper has been widely used for the development of several commercially available agricultural bio-/pesticides [3]. In the early 1970s, zinc salts for pesticide use were first registered in the United States. Later in the 1990s, the US Environment Protection Agency (US-EPA) approved three zinc salts, namely, zinc chloride, zinc oxide, and zinc sulfate for use as herbicide and the industrial preservative (to control spoilage by bacterial and fungal contaminants in carpets) [4]. Zinc phosphide, another $\mathrm{Zn}$-salt, is applied as an effective rodenticide [5,6]. Further, zinc oxide has been approved to be used as a stabilizer in pesticide formulations with concentration not exceeding $15 \%(w / w$ or $w / v)$ of the formulation [7]. Later, the zinc formulations have got popularized for the antimicrobial activity against various phytopathogens. The antimicrobial potential of the zinc formulations render its use as a considerably low cost, less environmentally toxic, and effective microbicide exhibiting broad-spectrum activities including bactericide [8], fungicide [9-11], or algaecide [12] and other activities. A growing interest exists for the development of novel zinc formulations possessing enhanced efficacy and action specificity. Generation and use of nanoenabled formulations of pesticides are one among the emerging and pertinent alternatives to manage plant diseases causing phytopathogens.

\subsection{Status of Use of Nanomaterials in Plant Pathology}

Changing climatic patterns and intensive agriculture has contributed enormously to the development of more fastidious and virulent pathogens, which exhibit resistance to several pesticides (bactericides, fungicides, and similar action compounds) [13-15]. These strains of microbes can survive through higher concentrations of the -cidal compounds/composites besides requiring multiple applications and therefore, have become a big menace for the farmers to avoid or control the yield losses caused by these pathogens [16]. The use of nanomaterials for control of phytopathogens has been envisioned by agriscientists after the evidence for -static to -cidal properties of various types of nanomaterials that appeared for human/livestock pathogens in journals of repute of biomedicine or pharmacology [17-21]. Amenability to fabrication/alteration of size and surface morphology and functionalization of nanomaterials is of tremendous significance considering the quick and sustainable eradication of pesticide-resistant phytopathogens [22-27].

Various categories of nanomaterials have been evaluated for their diverse agriapplications such as nanofertilizers, nanopesticides, and pesticides degradation to achieve plant growth promotion and protection [28] (Figure 1). Thus, the current manuscript entails the published research on the use of zinc nanomaterials for management and early diagnosis of phytopathogens. Further, the application of zinc nanomaterials as potent antimicrobial agents and their use for curbing the growth, virulence, and diseases caused by plant pathogens have been elaborated. The use of zinc nanomaterials as functional elements in biosensor systems for robust and sensitive identification of phytopathogens is also discussed. 


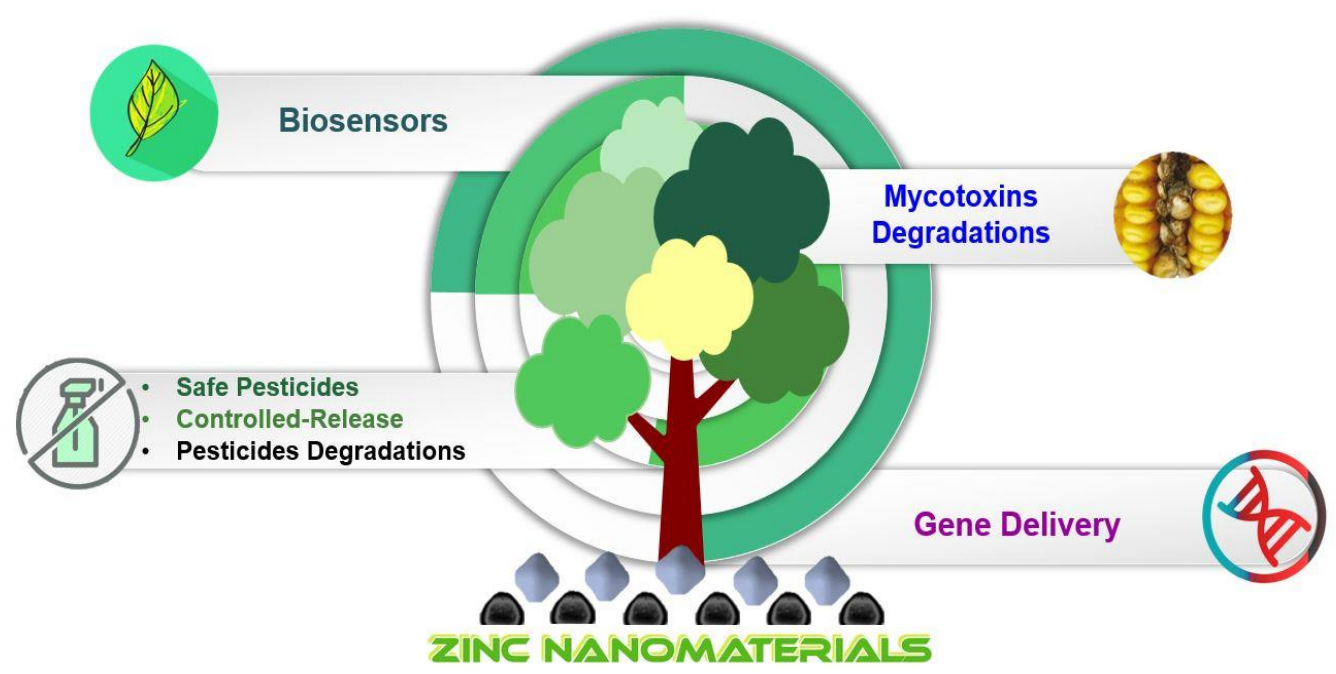

Figure 1. Zinc-based nanomaterials applications in plant pathology.

\section{Nanomaterials: Can Nanosizing Matter Alter Its Properties?}

Nanomaterials (NMs) exhibit enormous chemical diversity and can be categorized on basis of their chemical origin as natural, organic, synthetic, metal/nonmetal, or their oxides, sulfides, nitrides, and other forms [29]. These are considered as an intermediate state of matter with at least one of the size dimensions existing between size scales of 1-100 $\mathrm{nm}$. The dimensionality classification of NMs segregates these as zero-, one-, two- and three-dimensional materials $[30,31]$. The nanomaterials exhibit novel physical, chemical, and biological properties [32,33]. The reason for the unusual properties of nanomaterials may be attributed to the basic phenomena of "quantum confinement" and "surface-interface effects" [34-36]. These two characteristics may alter the mechanical, optical, electrical, magnetic, and chemical catalysis properties of nanoscale materials compared to their bulk counterparts $[37,38]$. Thus, nanomaterials exhibit properties that are size dependent, i.e., the size of grain or particles, phase inclusions, pores, or other morphological features affect the properties exhibited by the substance [39].

\subsection{Mechanism of Antimicrobial Activity}

The antimicrobial potential of the nanomaterials gets improved possibly due to enhanced surface of contact with the microbial surfaces or biomolecules [17,40,41]. On interaction with the microbial cells, NMs can adsorb to oppositely charged functional groups [42] and exhibit the advantage of trespassing the intact cell boundaries/membranes. Further, NMs can generate photocatalytic or redox driven electron/hole or electron-hole pair leading to the formation of reactive oxygen moieties (superoxide anion radicals, hydroxyl radicals, singlet ion, and hydrogen peroxide), which can cause random and rapid oxidation of diverse biomolecules of critical structural, functional, and hereditary role in the cell such as proteins, enzymes, lipids, and nucleic acids [25]. Alternatively, NMs may form complexes with the biomolecules leading to damage and inactivation of biomolecules particularly the proteins $[27,43]$. These interactions and transformations of the biomolecules result in inhibition of cell growth and division [44]. The distortion of the cell morphology and topography is a common feature epitomized by disruption of cellular membrane including exfoliation or erosion of the membrane bilayer structure, appearance of pits due to preferential dissolution of extrinsic proteins, and leakage of cell cytoplasm or even bursting of the cell [17] (Figure 2). Therefore, the complex cascades, diversity, and multiplicity of these interactions may not allow the pathogen to develop the neutralizing or counter-acting mechanisms to address all these interactions. Thus, NM-based antimicrobials will exhibit durable efficacy as there are fewer chances of development of profound resistance in the pathogen [25]. 


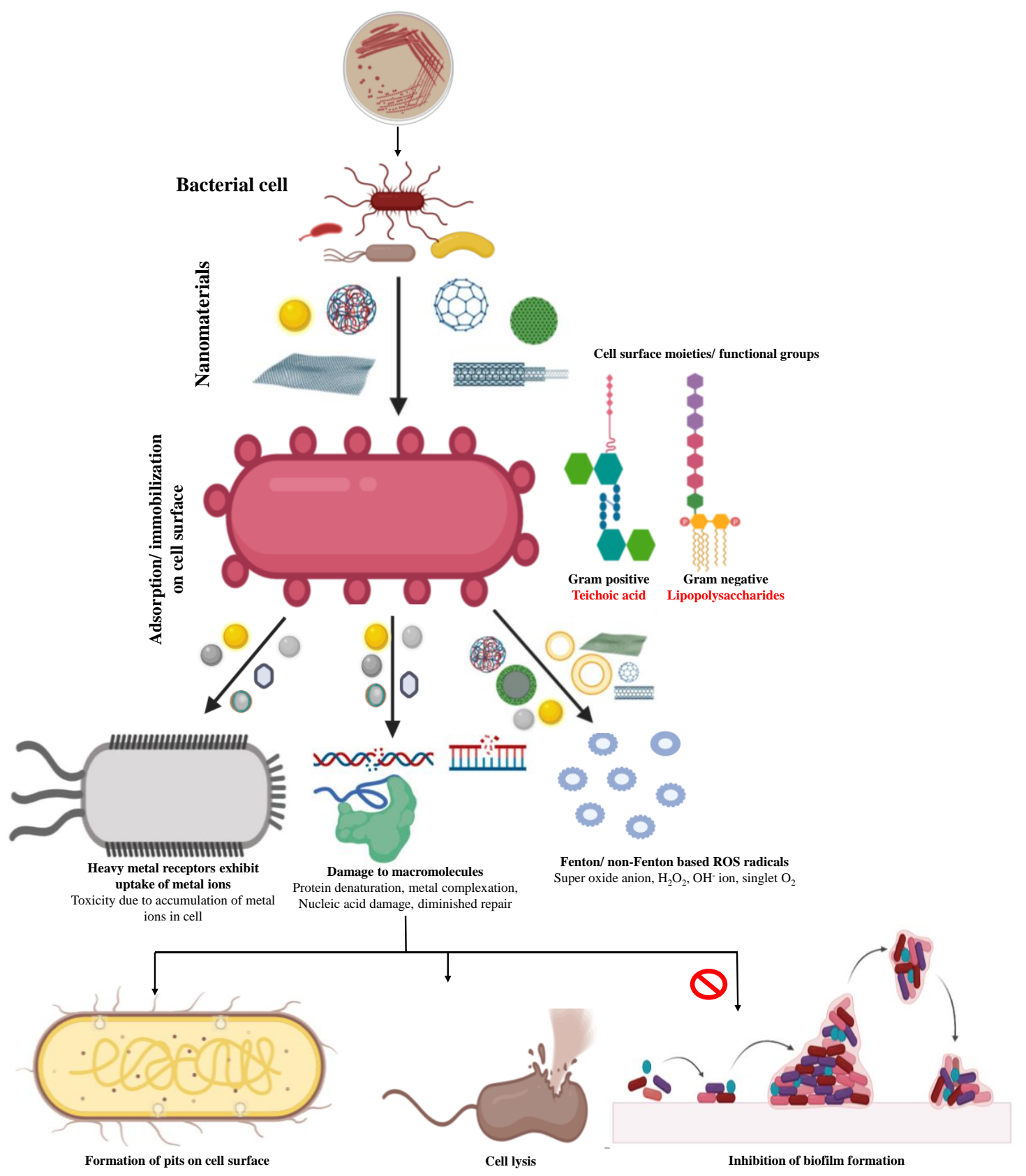

Figure 2. Mechanisms governing the antibacterial potential of different types of nanomaterials.

\subsubsection{Metal/Metal Oxides, Metalloid, and Nonmetal Nanomaterials}

Plants are affected by diverse biotic stress agents, particularly the phytopathogens that cause various diseases and claim the growth and yield losses in crop plants. The incidences of quick emergence of novel pesticide-resistant phytopathogens and reduced efficacy of already available arsenal of antipathogenic compounds/formulations have led towards a possibility of use of antimicrobial potentials of the nanomaterials to curb plant pathogen, which cause diseases culminating to high economic losses due to crop failure. Metal/metal oxide nanoparticles exhibit appreciable antimicrobial activities, which may span over -cidal to static potentials and help in curbing bacteria (bactericide) $[17,18]$, fungi (fungicide) [40], virus (viricidal) [45], and algae (algicidal) [46].

The antimicrobial effect of metal/metal oxide, metalloid, and nonmetal nanomaterials on the test pathogens have been reported to be size and dose dependent $[26,47,48]$. Further, substantially low concentrations of nanomaterials are required to achieve significantly improved antimicrobial efficacy 
as compared to the standard reference antimicrobial agent (such as antibiotics and pesticides) [8,49]. Interestingly, the combinatorial use of nanomaterials along with the conventional antimicrobial agents [50] or a combination of metal/metal oxide/nonmetal oxide NPs can enhance the action-spectrum and reduces the minimum inhibitory concentrations (MIC) values [51].

Among the various inorganic nanomaterials, the antimicrobial activity including the antimycotic potential of the noble metal nanoparticles $(\mathrm{Au} / \mathrm{Ag} \mathrm{NPs}$ ) against plant pathogenic microbes was identified initially [51-55]. Later, nanoparticles/nanomaterials of Group IIa metals including magnesium [56,57]; calcium [58]; other transition metals such as copper [57,59-62], iron [61], manganese [57], nickel [63,64], titanium [61,65], zinc [56,57,60,62,66-68], and zirconium [21,69]; and nonmetals such as silicon [57], selenium [70-73], and tellurium [74,75] have been evaluated for their antimicrobial potentials. However, chemically, physically, and biologically synthesized noble metal NPs (Au/Ag NPs), copper/copper oxide, zinc/zinc oxide NPs, and magnesium NPs have been mostly reported for the plant pathogenic microbes, whereas the rest of the NP-microbe studies involved evaluation of antimicrobial activity against human or food pathogenic microbial cultures.

\section{Mechanism of Antibacterial Activity of Nanomaterials}

Nanomaterials exhibit antibacterial potentials manifested as disintegration of the cell membrane leading to leakage of the cytoplasmic contents followed by the lysis of the bacterial cells $[47,76,77]$. Passive internalization of the NPs can occur through porin-ion channels in Gram-negative bacteria [78], whereas in Gram-positive bacteria, presence of thick cell wall hinders passive internalization and therefore, dissolved ionic species (e.g., $\mathrm{Zn}^{2+}, \mathrm{Cu}^{2+}$, and $\mathrm{Fe}^{2+}$ ions) released by the nanoparticles in vicinity of the cell surface get chelated by lipoteichoic acid [79]. Once inside the cell, the internalized NPs may elicit Fenton- or non-Fenton-based ROS-mediated damage of the plasma membrane, internal macromolecules, and other soluble and catalytic biomolecules [78]. Eventually or simultaneous release of ions by the dissolution of NPs leads to metal/nonmetal ion toxicity culminating to cell death $[25,76]$. Another interesting mechanism involves inhibited expression of the quorum-sensing regulated genes or functions in bacteria leading to inhibition of the biofilm formation $[41,80]$. The nanostructured materials can also help in the inhibition of the preformed biofilms of the plant pathogens, which is of great significance for the eradication of resistant bacterial pathogens [81] or pathogens related to food spoilage $[80,82]$.

\section{Mechanism of Antimycotic Activity of Nanomaterials}

Enormous literature on antifungal potential of nanoscale silver [52-54,59,83,84], copper/copper oxide [59,62], and zinc/zinc oxide [40] materials exists (Figure 3). The fundamental benefit of the nanoparticulate fungicide is the performance of these formulations equivalent or superior to the respective bulk salt formulations at relatively lower application doses thereby effectively addressing the phyto- and ecotoxicity issues posed due to the release of the metal cations [85]. There exist multiplexed nanomaterial-fungal cell interactions. The nanomaterial internalization in the fungal cell occurs through three possible mechanisms; (i) nonspecific but direct internalization of the small-sized, mostly, spherical nanoparticles, (ii) specific receptor-mediated adsorption followed by internalization of the NPs, or (iii) internalization of dissolved metal/nonmetal ions through membrane-spanning ion transport proteins (Figure 3). Nanomaterials particularly the metal/metal oxide and nonmetal oxide nanoparticles can curb fungal growth through mechanisms that can be dichotomized as (a) antimycotic effect due to generation of ROS and dissolution of the nanoparticles in the cell environment to release specific ions leading to metal/nonmetal ion toxicity and (b) regulation of the mycotoxin-producing genes for decreased or no expression. A detailed illustration of the same for zinc nanomaterials will be incorporated in Section 3. 


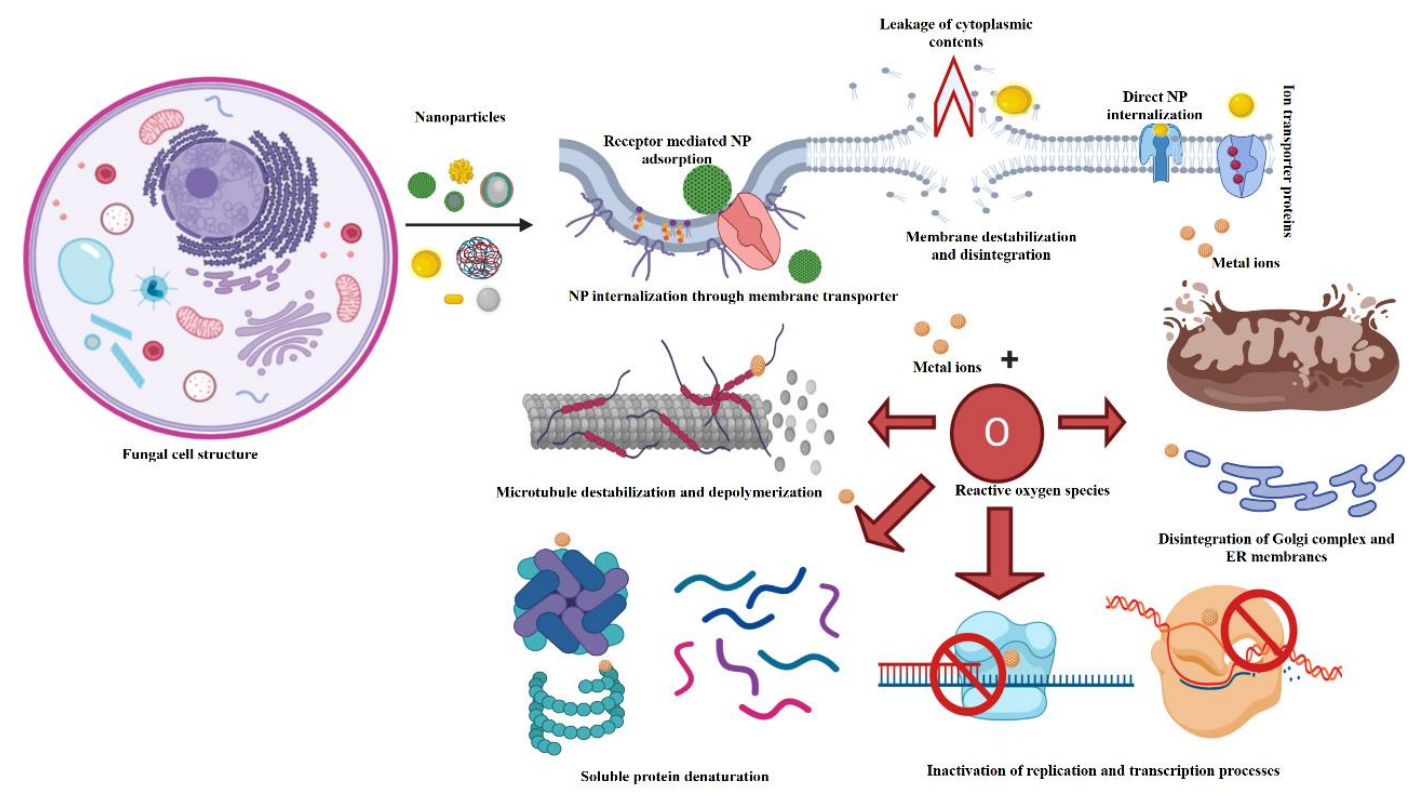

Figure 3. Effect of application of different types of nanoparticles on cellular components and organelles in a fungal cell.

Mechanism of Antiviral Activity of Nanomaterials

The M/MO/NM/NMO nanomaterials possess antiviral activity against microbial [86], animal [87-90], and human viruses [91-97] as depicted in several published reports. The green synthesized (microbial/plant cell extract-derived) nanoparticles particularly silver [98] and gold nanoparticles [99] or their composites [98] have been documented to exhibit virus-neutralizing or -inhibiting properties. Likewise, the role of zinc nanomaterials for the virostatic effect [100], virus neutralization, and for immune-modulatory significance against the emerging COVID-19 causative agent [101] has been well identified.

The application of nanomaterials for the control and treatment of viral disorders in crop plants has also been evaluated and established through molecular biology and in planta assays [45]. One-week preapplication of silver NPs at low concentration $(50 \mathrm{ppm})$ on tomato plants decreased the disease severity and induced systemic resistance against two common tomato viruses, namely, Tomato mosaic virus, and Potato virus Y [102]. However, another in planta study showed significant inhibition of Tomato spotted wilt virus on foliar spray of AgNPs (200 ppm) 1 day after artificial inoculation of the TSWV, whereas the lowest and substantially low inhibition was recorded when AgNPs were applied along with and before the virus inoculation, respectively [103]. Similar results have been documented by Elbeshehy et al. [104] on foliar spray treatment of biogenically synthesized AgNPs derived from cell-free extracts of three Bacillus bacteria species (B. pumilus, B. persicus, and B. licheniformis). Complete inhibition of typical disease symptoms was recorded when the AgNPs were applied (concentration:

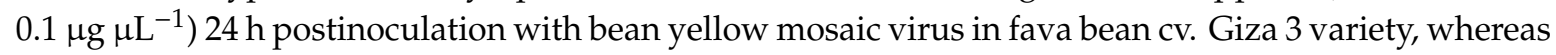
weak symptoms were recorded when AgNPs formulation was sprayed on foliage simultaneously to that of swab inoculation of the fava bean plants. Low concentration of fungus generated AgNPs formulation (derived from Curvularia lunata cell extracts, concentration: $100 \mathrm{ppm}$ ) on spray treatment on the foliage of approximately 1 month (35 days) old tobacco plants (Nicotiana tabacum cv. Xanthi nc) followed by mechanical inoculation of two leaves (5th and 6th true leaf) with PVY-Ros1 virus after 2 days resulted in 2.67-fold decrease in the appearance of characteristic red lesions/infection loci in AgNP-treated plants. Development of nano-Ag composites can further improve the antiviral activity, for instance, graphene oxide-AgNP composite treatment (at $1 \mu \mathrm{g} \mathrm{mL}^{-1}$ ) reduced the visible symptoms of disease caused by Tomato bushy stunt virus in test lettuce plants [105]. 
Apart from silver NPs, daily foliar spraying treatment for approximately 2 weeks (12 days) of micronutrient iron oxide NPs $\left(\mathrm{Fe}_{3} \mathrm{O}_{4} \mathrm{NPs}\right.$, size: $20 \mathrm{~nm}$, concentration: $\left.100 \mu \mathrm{g} \mathrm{mL}{ }^{-1}\right)$ enhanced the resistance of tobacco plants against Tobacco mosaic virus [106]. Another report involved daily foliar spray treatment on Nicotiana benthamiana plants with $\mathrm{Fe}_{2} \mathrm{O}_{3}$ (concentration: $50 \mathrm{mg} \mathrm{L}^{-1}$ ) or $\mathrm{TiO}_{2} \mathrm{NPs}$ (concentration: $200 \mathrm{mg} \mathrm{L}^{-1}$ ) (amount: $5 \mathrm{~mL}$ ) for 21 days. When these plants were challenged with Turnip mosaic virus (green fluorescent protein-tagged TuMV), the plants exhibited significant inhibition in the proliferation of the inoculated TuMV, particularly decrease in coat protein content as identified through a decrease in the fluorescent intensity of GFP marker in new emerging leaves [107].

\section{Zinc Nanomaterials and Their Use for Curbing Plant Disease-Causing Pathogens}

Metal oxides exhibit substantially high antimicrobial activities. However, the eco- and cytotoxicity aspects associated with the application of these novel antimicrobial formulations have hampered their quick commercial applications. Among the various metal oxides, $\mathrm{ZnO}$ nanoparticles appear to be one of the most propitious candidates as these NPs can be generated through low-cost synthesis techniques in bulk amounts. Further, their better biosafety and lower cytotoxicity indices for mammalian cells have been proven through several cell line studies [108-110] including the report on the preferential killing of human cancer cells compared to normal cells by ZnO NPs [109]. The antimicrobial action spectrum of Zn nanomaterials includes antibacterial, antifungal, and antiviral characteristics [111]. Therefore, the research insights on relative multifunctional properties of the zinc nanomaterials exhibiting antimicrobial actions are based on a fundamental hypothesis of spontaneous generation of ROS species and intracellular oxidative stress leading to killing of the microbial cells [79,112].

\subsection{Antibacterial and Mollicute Controlling Potential}

The studies involving zinc nanomaterial-antibacterial assay against plant pathogenic bacteria are scarcely reported as the majority published research includes the antibacterial activity against pathogenic bacterial genera/species causing human or animal health diseases [113-115]. However, plant pathogenic bacteria-Zn nanomaterial interactions have been studied including the reports showcasing the inhibitory effect on the causative agent of citrus canker (Xanthomonas citri subsp. citri) [116], rice leaf blight pathogen (Xanthomonas oryzae pv. oryzae) [81], tomato bacterial spot pathogen (copper-tolerant strains of Xanthomonas perforans) [117], the causative agent of lentil bacterial leaf spot (Xanthomonas axonopodis pv. phaseoli) [118], the causative agent of bacterial blight of lentil (Pseudomonas syringae pv. syringae) [118], and eggplant bacterial wilt pathogen (Ralstonia solanacearum) [119].

On the evaluation of the relative antibacterial potential of the Zn-nanomaterials, studies established higher efficacy in comparison to the absolute or conventional bulk controls. Among the green synthesized ZnO NPs derived from three different plant extracts, Olea europaea extract-derived ZnO NPs exhibited the highest inhibition zone $\left(2.2 \mathrm{~cm}\right.$ at $\left.16.0 \mathrm{mg} \mathrm{mL}^{-1}\right)$ for Xanthomonas oryzae pv. oryzae [81]. Likewise, Graham et al. [108] have compared the relative efficacy of nano-ZnO formulations, Zinkicide SG4 and SG6, in an in vitro assay and showed twofold and eightfold lower MIC for SG4 and SG6, respectively, against $X$. alfalfae subsp. citrumelonis.

The antibiofilm forming potential of nanozinc material is of remarkable significance for commercial application. The specific benefit of the antibiofilm property of the zinc nanomaterials [82] spans over the decontamination of the food articles [82], surfaces [120,121], produce processing equipment [122], and packaging systems [80,123-125].

Apart from the bacterial pathogens, the crop plants are also affected by obligate parasitic, axenically unculturable prokaryotic cell wall lacking eubacterial plant pathogens [126], the "phytoplasma" or "mollicutes" [127], which are associated with $>600$ plant diseases across the globe [128-131]. These initially classified as wall-less bacteria possess a trilaminated unit membrane, a small genome ( $\sim 680$ to $1600 \mathrm{~kb}$ ), exhibit morphological pleomorphism (size ranging between 0.2 and $0.8 \mu \mathrm{m}$, and shapes varying from helical, filamentous, beaded, or simply spheroid), dwell in sieve tubes [132] and therefore, 
are mainly transmitted by phloem sap-feeding or sucking pest vectors, particularly planthoppers and psyllids, and by vegetatively propagated grafts or tissues $[133,134]$. Being obligate parasites, phytoplasma diseases can be effectively controlled by managing the vector pest population. Therefore, research efforts to develop RNAi- or dsRNA-based nanoenabled pesticides have been initiated that can effectively control the psyllids and/or leafhopper population $[135,136]$. However, a few reports have appeared including the development and use of nanoemulsion formulations of antibiotics [137], essential oil or aldehyde compounds (such as cinnamaldehyde), and silver nanoparticles [138] for management or eradication of Candidatus liberibacter asiaticus causing Huanglongbing or citrus greening disease. Foliar spray and trunk injection treatments of zinc oxide and zinc sulfide nanoparticles alone as an isopropanol-based emulsion or in combination with cinnamaldehyde-isopropanol have been reported to effectively decrease the occurrence of this bacteria in the phloem tissue [139]. Likewise, published reports indicated in planta inhibition of Candidatus liberibacter asiaticus by trunk injection application of aqueous formulations of $4 \mathrm{~nm}$-sized zinc oxide nanoparticles and ZnONP-2S albumin protein composite [140]. A qPCR assay revealed that 1:1 proportion of ZnONPs: $2 S$ albumin (concentration of $330 \mathrm{ppm}$ each) most effectively decreased the bacterial pathogen to about $97 \%$ of the initial concentration.

\subsection{Antimycotic and Mycotoxin Neutralizing/Inhibiting Activity}

The antimycotic potential of zinc oxide nanoparticles or its composites has been well identified against phytopathogenic fungi belonging to diverse taxonomic groups/classes such as zygomycetous oomycetes genera (Peronospora tabacina [141], Pythium ultimum, Pythium aphanidermatum [142]), ascomyceteous genera (Alternaria alternata [59,62], Aspergillus flavus/A. fumigatus [51], Aspergillus niger [143], Botrytis cinerea [61,62,144,145], Colletotrichum gloeosporioides [56,59], Fusarium graminearum [146], Fusarium moniliforme [40], Fusarium oxysporum [66,144,147], Penicillium expansum $[50,66,144,148])$, and basidiomycetous genera (Erythricium salmonicolor [68]).

Zinc-derived nanomaterials (nanoparticles/composites) at substantially low working concentrations can kill spores or exhibit inhibition of spore germination (sporostatic/sporicidal activities) besides inhibiting the vegetative mycelial growth of the filamentous fungal plant pathogens, e.g., a significant decrease in fungal growth of $B$. cinerea and P. expansum has been observed on ZnO NPs ( $3 \mathrm{mM} \mathrm{L}^{-1}$ concentration) treatment [144]. Likewise, events of spore germination of Peronospora tabacina were observed to be completely inhibited on treatment with $\mathrm{Zn} \mathrm{NPs}, \mathrm{ZnO} N P s$, and $\mathrm{ZnCl}_{2}$ soluble salt at concentrations ranging from $15-20 \mathrm{mg} \mathrm{L}^{-1}$ [141].

\subsubsection{Mechanism of Antimycotic Activity}

Multifarious mechanisms govern the antimycotic activity of the zinc nanomaterials. The primary inhibitory symptoms that appear postincubation of an alive culture of fungi with nanoscale zinc/zinc oxide material include adsorption of nanozinc on the hyphal cell surface, hyphal deformation leading to morphological alterations in the cell wall and cell membrane, formation of sunken or swollen mycelia besides extensive thinning, and branching of the mycelia [144]. The same could be or may not be accompanied by suppression of spore or conidia-forming structures or formation of distorted sporangiophore/conidiophore and absence of formation of perennation structures (spores/conidia) or their number is decreased. Fungal spore nanozinc incubation studies have revealed a delay in spore germination, formation of abnormal stout/short germination tubes, or complete inhibition of spore germination indicating the sporistatic to sporicidal properties of nanoscale $\mathrm{Zn}$ material [141].

At the cell ultrastructural level, changes in the cell wall and membrane structure epitomized as enhanced thickening of the cell wall, liquefaction of cell membrane, dissolution or disorganization of the cytoplasmic organelles, hypervacuolization, and detachment of cell wall from cytoplasmic contents indicating incipient plasmolysis like features appear [68].

At the molecular biology scale, the nanoscale $\mathrm{Zn}$ materials exhibit interactions with a variety of biomolecules leading to complexation with structural and soluble proteins, inactivation of catalytic 
proteins, ROS-mediated damage to nucleic acid, particularly the scission of DNA strand, and breakage leading to chromosomal aberrations $[25,143,149]$. Interaction of zinc nanomaterials with the hyphal cell surfaces also specifically elicit synthesis of nucleic acid and/or production/secretion of the carbohydrates as depicted through increased Raman spectra signal intensities corresponding to these biomolecules [144]. The production of these components may indicate the increased expression of genes involved in subduing the ROS damage induced by the nanozinc material, particularly the osmolytes such as trehalose oligosaccharide. Further, the cell growth cycle also gets altered thereby inhibiting cell division.

\subsubsection{Mycotoxin Neutralizing/Inhibiting Activity}

The effect of nanoscale zinc materials for mycotoxin production by the filamentous fungal hyphae have also been evaluated [150,151]. Mycotoxins exhibit enormous structural and chemical diversity. Several fungal genera produce different types of mycotoxins primarily including aflatoxins (B1, B2, G1, G2, and M10), ochratoxins, deoxynivalenol, trichothecenes produced by ascomycetous genera Aspergillus (sexual stage name: Eurotium) [152]. Likewise, various species of another ascomycetous fungus, Penicillium (sexual stage name: Eupenicillium), synthesizes and secretes a variety of secondary molecules considered as mycotoxins such as penicillic acid, brevianamide A, griseofulvin, patulin, citreoviridin, citrinin, roquefortine, cyclopiazonic acid, PR-toxin, fumitremorgin B, penitrem A, luteoskyrin, ochratoxin A, rugulosin, verrucosidin, verruculogen, viridicarumtoxin, and xanthomegnin [153,154]. Ascomycetous member belonging to order Hypocreales, Fusarium, produces trichothecenes (including fumonisins, zearalenone, deoxynivalenol, and diacetoxyscirpenol) besides fusaproliferin, beauvericin, enniatins, and moniliformin [155]. Alkaloids of Claviceps sp. are also considered mycotoxins and include clavines, lysergic acids and their amides, and ergopeptides [156-158]. Besides these genera, Alternaria sp. produces diverse types of mycotoxins such as altenuene, alternariol, and its methyl ether, altertoxin, and tenuazonic acid [159].

The engineered NPs including ZnO NPs can control mycotoxin production by the mycotoxigenic fungi besides neutralization or adsorption of already formed/secreted mycotoxins [160] (Figure 4). The antimycotic potential of the nano-Zn formulations has already been discussed in Section 3.2.1. The other two mechanisms that are directly responsible for alteration in mycotoxin production by the mycotoxigenic fungi on supplementation of nanozinc formulations in culture/growth media will be dealt with here. Metal oxide nanoparticles exhibit classical size quantization effect such that discrete energy state appears and the number of surface atoms to bulk ratio gets altered besides the changes in the surface topology, which result in enhancing the reactive surface area [161]. Likewise, the thermodynamics of chemical reactivity is varied due to variations in the surface free energy of the NPs. These features adorn NPs the excellent adsorption characteristics. Though classically, carbon nanomaterials, including the amorphous carbon, graphene oxide, carbon nanotubes, and carbon fullerol nanoparticles [150], carbon nanocomposites [162], and inorganic nanocomposites such as $\mathrm{MgO}-S i O_{2}$ nanocomposite [163] and organo-silicate composites [164], exhibit higher potential for mycotoxin adsorption. However, a recent study on the application of fullerol nanoparticles (FNP) on the aflatoxin biosynthetic pathway in Aspergillus flavus has been performed which suggested a concentration-dependent eliciting effect of FNP on aflatoxin synthesis after $120 \mathrm{~h}$ of incubation [165]. Therefore, other nanoadsorbent alternatives including the metal and metal oxides particularly the iron, copper, silver, and the zinc NPs $[150,166]$ can be evaluated for mycotoxin adsorption and removal. A research study on flower-shaped zinc nanostructures (Znstr) revealed that supplementation of low concentrations of $Z n s t r(1.25,2.5$, and $5.0 \mathrm{mM})$ in the liquid growth media led to substantial suppression $(97 \%)$ of aflatoxin biosynthesis by Aspergillus flavus besides reducing the content of aflatoxin $(69 \%)$ in maize grains [167]. 


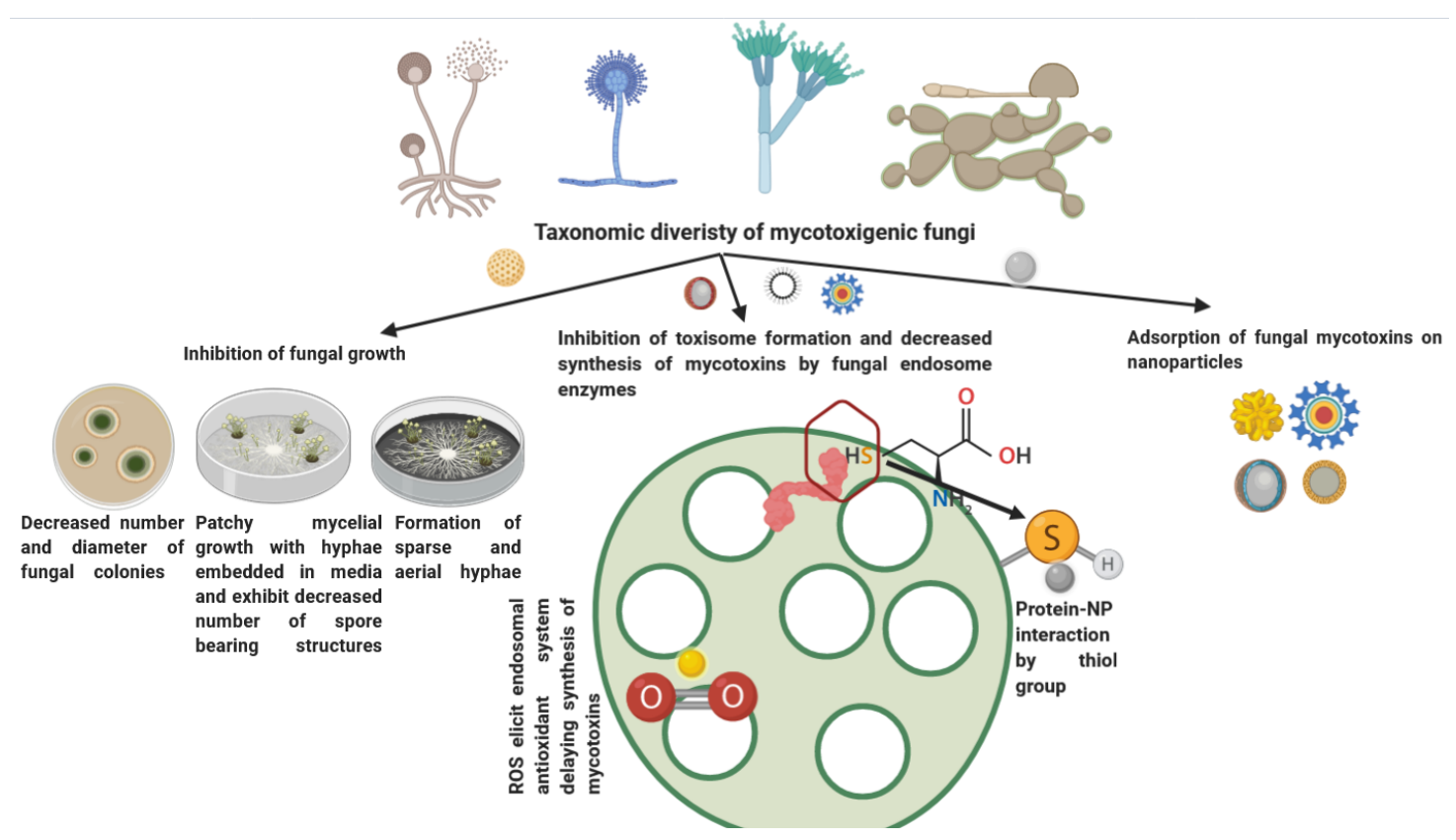

Figure 4. Zinc nanomaterials can exhibit a threefold impact on the production and neutralization of mycotoxins produced by mycotoxigenic fungi.

Apart from the use of nanomaterials for adsorption of mycotoxins, a recent study deciphering the mycotoxin inhibition mechanism of the AgNPs reported a fungus-growth-independent decrease in the aflatoxin B1 production in Aspergillus parasiticus [160,168,169]. Unlike the above study, a report documented inhibition of both growth and mycotoxin production potential of Fusarium graminearum on the application of biogenic zinc oxide nanoparticles [170]. However, Savi et al. [168] have reported appreciable antifungal and antimycotoxigenic potential of various zinc compounds against Fusarium graminearum, Aspergillus flavus, and Penicillium citrinum. Therefore, zinc nanomaterials have great potential for curbing the growth and mycotoxin contamination of food and feed material [171].

\subsubsection{Zinc Nanomaterials for Curbing Plant Viruses/Viroid Diseases}

Viruses and viroids cause diverse diseases in crop plants on infection and are responsible for enormous losses posing a great threat to crop productivity and food security. Further, there is a lack of an effective plant viral disease control strategy besides the occurrence of a few commercial antiviral formulations, which enhance the threat for effective control of plant viral diseases. The use of nanomaterials for curbing the spread and disease severity of plant viruses is rather in its incipient stage and research reports on the use of silver [102,103], silver-graphene composite [105], iron oxide [172], and $\mathrm{Fe}_{3} \mathrm{O}_{4}$ [106] nanomaterials have been published. However, there is one recent report on the application of zinc oxide nanoparticles on the plant foliage to curb Tobacco mosaic virus infection in Nicotiana benthamiana [45]. The details regarding the antimicrobial potential of various zinc nanomaterials against plant pathogens have been summarized and presented in Table 1. 
Table 1. Antimicrobial potential of zinc nanomaterials on plant pathogenic microbes.

\begin{tabular}{|c|c|c|c|c|c|c|c|c|}
\hline $\begin{array}{c}\text { Type of } \\
\text { Zn-Nanomaterial Used }\end{array}$ & $\begin{array}{l}\text { Zn-Nanomaterial } \\
\text { Characterization }\end{array}$ & $\begin{array}{c}\text { Working } \\
\text { Concentration }\end{array}$ & $\begin{array}{c}\text { Study Conditions } \\
\text { (Exposure Technique) }\end{array}$ & $\begin{array}{c}\text { Zn-Nanomaterial } \\
\text { Application Method }\end{array}$ & $\begin{array}{c}\text { Pathogen Inoculation } \\
\text { Technique }\end{array}$ & Pathogen Studied & Impact & References \\
\hline \multicolumn{9}{|c|}{ Bacterial pathogens } \\
\hline $\begin{array}{l}\text { Zinkicide SG4, } \\
\text { Zinkicide SG6 }\end{array}$ & $\begin{array}{l}\text { 2-D nanoplate-like } \\
\text { structure } \\
\text { (dimensions: } \\
0.2-0.5 \mathrm{~mm}, \\
\text { thickness: } \sim 10.0 \mathrm{~nm} \text { ) } \\
\text { nanoparticulate } \\
\text { (size: } 4-6 \mathrm{~nm} \text { ) }\end{array}$ & 2000 to $1.96 \mathrm{mg} / \mathrm{mL}$ & $\begin{array}{c}\text { In vitro assay } \\
\text { (broth microdilution } \\
\text { technique) }\end{array}$ & $\begin{array}{l}\text { Addition in broth at } \\
\text { different working } \\
\text { concentrations }\end{array}$ & Broth inoculation & $\begin{array}{l}\text { X. alfalfae subsp. } \\
\text { citrumelonis }\end{array}$ & $\begin{array}{l}\text { Two-fold and 7/8-fold } \\
\text { lower MIC for } \\
\text { Zinkicide SG4 and } \\
\text { SG6, respectively }\end{array}$ & [116] \\
\hline $\mathrm{ZnONPs}$ & $\begin{array}{c}\text { Commercial } \\
\text { formulation } \\
\text { (size }<100 \mathrm{~nm} \text { ) }\end{array}$ & $0.1 \mathrm{mg} \mathrm{mL}^{-1}$ & In planta assay & $\begin{array}{l}\text { Foliar spray of } \mathrm{ZnO} \mathrm{NPs} \\
\text { suspension (10 mL per } \\
\text { lentil plant) under pot } \\
\text { culture conditions }\end{array}$ & $\begin{array}{l}\text { Nutrient broth culture } \\
\left(10 \mathrm{~mL}^{\circ} 1.2 \times 10^{5}\right. \\
\left.\mathrm{CFU} \mathrm{mL} \mathrm{mL}^{-1}\right) \text { added } \\
\text { around the seedling }\end{array}$ & $\begin{array}{c}\text { Xanthomonas axonopodis } \\
\text { pv. phaseoli }\end{array}$ & $\begin{array}{l}\text { Reduction in disease } \\
\text { severity on } \\
\text { pathogen challenge }\end{array}$ & [118] \\
\hline $\begin{array}{l}\text { Zinkicide SG4, } \\
\text { Zinkicide SG6 }\end{array}$ & $\begin{array}{l}\text { 2-D nanoplate-like } \\
\text { structure } \\
\text { (dimensions: } \\
0.2-0.5 \mathrm{~mm}, \\
\text { thickness: } \sim 10.0 \mathrm{~nm} \text { ) } \\
\text { nanoparticulate } \\
\text { (size: } 4-6 \mathrm{~nm} \text { ) }\end{array}$ & $\mathrm{Zn}(30 \% w / v)$ & In planta assay & $\begin{array}{l}\text {-Foliar spray of } \mathrm{Zn} \\
\text { formulation (10 mL per } \\
\text { grapefruit seedling) } \\
\text { using air-brush in } \\
\text { greenhouse assay } \\
\text {-Foliar spray of } \mathrm{Zn} \\
\text { formulations ( } 3.0 \mathrm{~L} \mathrm{per} \\
\text { grapefruit tree) with a } \\
\text { handgun sprayer }\end{array}$ & $\begin{array}{l}\text { Broth culture } \\
\left(10^{4} \mathrm{CFU} \mathrm{mL} \mathrm{mL}^{-1}\right) \text { in PBS } \\
\text { injection-infiltrated in } \\
\text { midrib of leaf } 3 \text { each site } \\
\text { at both surfaces }\end{array}$ & $\begin{array}{l}\text { Xanthomonas citri } \\
\text { subsp. citri }\end{array}$ & $\begin{array}{l}\text {-Reduction in citrus } \\
\text { canker disease } \\
\text {-Effective disease } \\
\text { control comparable or } \\
\text { better than } \\
\mathrm{Cu}_{2} \mathrm{O} / \mathrm{Cu}_{2} \mathrm{O}-\mathrm{ZnO} \\
\text { bactericides (no } \\
\text { phytotoxicity) }\end{array}$ & [116] \\
\hline ZnONPs & TEM: $41-51 \mathrm{~nm}$ & 4,8 , and $16 \mu \mathrm{g} \mathrm{mL}-1$ & In vitro assay & $\begin{array}{l}\text { Variable concentrations } \\
\text { of ZnO NPs }(10 \mu \mathrm{L} \text { each) } \\
\text { dropped on } 1 \text {-day old } \\
\text { bacterial lawn culture }\end{array}$ & $\begin{array}{l}\text { Lawn growth obtained by } \\
\text { spread plating of }(100 \mu \mathrm{L} \text {, } \\
\left.10^{8} \mathrm{cfu} \mathrm{mL}^{-1}\right) \text { broth } \\
\text { culture followed by } \\
\text { incubation for } 24 \mathrm{~h}\end{array}$ & $\begin{array}{l}\text { Xanthomonas oryzae pv. } \\
\text { oryzae (strain GZ 0003) }\end{array}$ & $\begin{array}{c}\text { Effective } \\
\text { antimicrobial agent } \\
\text { for bacterial leaf } \\
\text { blight of rice }\end{array}$ & [81] \\
\hline Cu-Zn hybrid NPs & TEM: 40-100 nm & $\begin{array}{l}1000,500,200 \\
\text { and } 100 \mu \mathrm{gL}^{-1}\end{array}$ & In vitro assay & $\begin{array}{l}\text { NP formulations added } \\
\text { to broth at different } \\
\text { concentrations }\end{array}$ & $\begin{array}{l}\text { Broth culture }(20 \mu \mathrm{L} \\
\left.10^{5} \mathrm{CFU} \mathrm{mL}^{-1}\right)\end{array}$ & $\begin{array}{l}\text { Xanthomonas perforans } \\
\text { (Cu-tolerant GEV485) }\end{array}$ & $\begin{array}{l}\text { Complete inhibition } \\
\text { of growth till } 24 \mathrm{~h} \text { of } \\
\text { incubation }\end{array}$ & [117] \\
\hline Cu-Zn hybrid NPs & TEM: $40-100 \mathrm{~nm}$ & $\begin{array}{l}500,200,100 \\
\text { and } 50 \mu \mathrm{mL}^{-1}\end{array}$ & In planta assay & $\begin{array}{l}\text { Foliar spray on 4-week } \\
\text { old seedlings of tomato } \\
\text { variety FL } 47 \text { under } \\
\text { growth chamber } \\
\text { conditions }\end{array}$ & $\begin{array}{c}\text { Pathogen } \\
\text { inoculation-foliar spray }\end{array}$ & $\begin{array}{l}\text { Xanthomonas perforans } \\
\text { (Cu-tolerant GEV485) }\end{array}$ & $\begin{array}{c}\text { Statistically highest } \\
\text { decrease in disease } \\
\text { symptoms at } \\
500 \mu \mathrm{g} / \mathrm{mL}\end{array}$ & [117] \\
\hline \multicolumn{9}{|c|}{ Fungal pathogens } \\
\hline $\mathrm{ZnONPs}$ & $\begin{array}{l}\text { Commercial } \\
\text { formulation } \\
(<50 \mathrm{~nm} \\
\text { particles size })\end{array}$ & $\begin{array}{l}0,1,10,100,500 \\
\text { and } 1000 \mu \mathrm{g} / \mathrm{mL}\end{array}$ & $\begin{array}{c}\text { In vitro assay } \\
\text { (poison food technique) }\end{array}$ & $\begin{array}{l}\text { Supplementation of PDA } \\
\text { with different working } \\
\text { concentrations }\end{array}$ & $\begin{array}{l}\text { Mycelial plug }(5 \mathrm{~mm}) \text { cut } \\
\text { from master culture PDA } \\
\text { plate (4-day old growth } \\
\text { from edge) }\end{array}$ & Alternaria alternata & $\begin{array}{c}\text {-Mean inhibition rate } \\
\left(\mathrm{EC}_{50}\right) \text { range } 235 \text { and } \\
848 \mu \mathrm{g} / \mathrm{mL} \\
\text {-higher efficacy } \\
\text { compared to } \mathrm{ZnSO}_{4}\end{array}$ & [59] \\
\hline
\end{tabular}


Table 1. Cont

\begin{tabular}{|c|c|c|c|c|c|c|c|c|}
\hline $\begin{array}{c}\text { Type of } \\
\text { Zn-Nanomaterial Used }\end{array}$ & $\begin{array}{l}\text { Zn-Nanomaterial } \\
\text { Characterization }\end{array}$ & $\begin{array}{c}\text { Working } \\
\text { Concentration }\end{array}$ & $\begin{array}{c}\text { Study Conditions } \\
\text { (Exposure Technique) }\end{array}$ & $\begin{array}{c}\text { Zn-Nanomaterial } \\
\text { Application Method }\end{array}$ & $\begin{array}{c}\text { Pathogen Inoculation } \\
\text { Technique }\end{array}$ & Pathogen Studied & Impact & References \\
\hline $\mathrm{ZnO}$ NPs/CS-Zn-CuNPs & $\begin{array}{l}\text { DLS: } 1.5-20 \mathrm{~nm} \\
\text { TEM: } 6-21 \mathrm{~nm}\end{array}$ & $\begin{array}{l}\text { 0, 30, 60, } \\
\text { and } 90 \mu \mathrm{gg} \mathrm{mL} \mathrm{L}^{-1}\end{array}$ & $\begin{array}{c}\text { In vitro assay } \\
\text { (poison food technique) }\end{array}$ & $\begin{array}{l}\text { Addition various } \\
\text { working concentrations } \\
\text { of prepared } \\
\text { nanomaterials in } \\
\text { PDA media }\end{array}$ & $\begin{array}{l}\text { Mycelial plug }(5 \mathrm{~mm}) \text { cut } \\
\text { from edge of } 1 \text {-week old } \\
\text { fungal growth on } \\
\text { PDA media }\end{array}$ & $\begin{array}{l}\text { Alternaria alternata, } \\
\text { B. cinerea, } R \text {. solani }\end{array}$ & $\begin{array}{l}\text {-Highest mycelial } \\
\text { inhibition by chitosan } \\
\text { mixed } \mathrm{Zn}-\mathrm{Cu} \\
\text { nanocomposite }\end{array}$ & [62] \\
\hline $\begin{array}{c}\text { 3D flower-shaped } \\
\text { nanostructured } \mathrm{ZnO}\end{array}$ & $\begin{array}{c}\text { FE-SEM: } \\
\text { 700-800 nm } \\
\text { XRD: crystallite } \\
\text { size- } 42.0 \pm 0.8 \mathrm{~nm}\end{array}$ & $0.3125-5.0 \mathrm{mM}$ & $\begin{array}{l}\text { In vitro assay } \\
\text { (broth culture } \\
\text { experiment) }\end{array}$ & $\begin{array}{l}\text { Supplementation of broth } \\
\text { with different } \\
\text { concentrations of } \mathrm{Zn} \\
\text { nanomaterial }\end{array}$ & $\begin{array}{c}\text { Aqueous conidial } \\
\text { suspension }(125 \mu \mathrm{L}, \\
\left.4 \times 10^{6} \text { spores } \mathrm{mL}^{-1}\right) \\
\text { added to Sabouraud } \\
\text { dextrose broth }(100 \mathrm{~mL})\end{array}$ & $\begin{array}{l}\text { Aspergillus flavus Link } \\
\text { (UNIGRAS-1231) }\end{array}$ & $\begin{array}{c}\text {-For } 1.25-5.0 \mathrm{mM} \\
\text { concentrations } \\
-78.0 \% \text { decrease in } \\
\text { mycelial growth } \\
-99.7 \% \text { decrease in } \\
\text { aflatoxin synthesis }\end{array}$ & [167] \\
\hline $\begin{array}{l}\text { Metallic }(\mathrm{Au} / \mathrm{Ag}) \text { and } \\
\mathrm{ZnO} \mathrm{NPs}\end{array}$ & $\begin{array}{l}\text { Commercial } \\
\text { formulation } \\
\text { DLS: } 7 \text { and } 477 \mathrm{~nm}, \\
\text { respectively }\end{array}$ & $50: 10 \mu \mathrm{g} / \mathrm{mL}$ & $\begin{array}{c}\text { In vitro assay } \\
\text { (A. broth microtiter } \\
\text { plate test, } \\
\text { B. Kirby-Bauer disk } \\
\text { diffusion technique) }\end{array}$ & $\begin{array}{l}\text { A. NP suspension }(20 \mu \mathrm{L} \\
\text { in } 75 \mu \mathrm{L} \text { SDB }) \\
\text { B. NP impregnated on } \\
\text { sterilized filter paper } \\
\text { disks (6 mm diameter) }\end{array}$ & $\begin{array}{c}\text { A. Spore suspension } \\
\left(5 \mu \mathrm{L}, 1 \times 10^{5} \text { spores/well }\right) \\
\text { B. Spread plating of spore } \\
\text { suspension }\end{array}$ & $\begin{array}{c}\text { Aspergillus flavus } \\
\text { (NRRL 3518)/A. } \\
\text { fumigatus } \\
\text { (ATCC 1022) }\end{array}$ & $\begin{array}{c}\text {-combination of mix } \\
\text { metallic NPs and } \\
\text { ZnO-NPs effectively } \\
\text { inhibited the } \\
\text { fungal growth } \\
\end{array}$ & [51] \\
\hline ZNPs & $\begin{array}{l}\text { DLS: } 30-40 \mathrm{~nm} \\
\text { TEM: } 15-20 \mathrm{~nm} \\
\text { (average particle } \\
\text { size) }\end{array}$ & $\begin{array}{c}50,100,250 \text {, and } 500 \\
\text { ppm }\end{array}$ & $\begin{array}{c}\text { In vitro assay } \\
\text { (poison food technique) }\end{array}$ & $\begin{array}{l}\text { Different } \mathrm{ZnO} \text { NPs } \\
\text { concentrations mixed in } \\
\text { sterilized PDA media }\end{array}$ & $\begin{array}{c}\text { Fungal spore suspension } \\
\left(3 \mu \mathrm{L}, \sim 10^{4} \mathrm{~mL}^{-1}\right) \text { spot } \\
\text { plated in center of PDA } \\
\text { media plate }\end{array}$ & Aspergillus niger & $\begin{array}{l}\text {-dose-dependent } \\
\text { decrease in radial } \\
\text { growth diameter }\end{array}$ & [143] \\
\hline $\mathrm{ZnONPs}$ & $\begin{array}{l}\text { Commercial } \\
\text { formulation } \\
\text { (TEM: } 70 \pm 15 \mathrm{~nm} \text { ) }\end{array}$ & $\begin{array}{l}0,3,6 \\
\text { and } 12 \mathrm{mM} \mathrm{L}^{-1}\end{array}$ & $\begin{array}{c}\text { In vitro assay } \\
\text { (poison food technique) }\end{array}$ & $\begin{array}{l}\text { ZnO NPs mixed in } \\
\text { different concentrations } \\
\text { in PDA media }\end{array}$ & $\begin{array}{c}\text { Aqueous spore } \\
\text { suspension }\left(\sim 10^{4} \mathrm{~mL}^{-1}\right)\end{array}$ & $\begin{array}{c}\text { Aspergillus niger } \\
\text { (MTCC-10180), } \\
\text { Fusarium oxysporum } \\
\text { (NCIM-1043, } \\
\text { NCIM-1072) }\end{array}$ & $\begin{array}{l}\text {-Significant inhibition } \\
\text { in hyphal growth at } \\
\text { concentration of } \\
3 \mathrm{mM} \mathrm{L}^{-1}\end{array}$ & [144] \\
\hline $\mathrm{ZnONPs}$ & $\begin{array}{l}\text { Leaf extract of } \\
\text { derived NPs }\end{array}$ & $\begin{array}{l}200,300 \text { and } \\
400 \mu \mathrm{gL}^{-1}\end{array}$ & $\begin{array}{c}\text { In vitro assay } \\
\text { (poison food technique) }\end{array}$ & $\begin{array}{l}\text { Supplementation of PDA } \\
\text { with different working } \\
\text { concentrations of NPs }\end{array}$ & $\begin{array}{l}\text { Fungal disc ( } 5 \mathrm{~mm} \\
\text { diameter) from 5-day old } \\
\text { culture growth }\end{array}$ & $\begin{array}{l}\text { Alternaria alternata, } \\
\text { Botrytis cinerea }\end{array}$ & $\begin{array}{l}\text {-Concentration-dependent } \\
\text { decrease in fungal } \\
\text { growth }\end{array}$ & [145] \\
\hline $\begin{array}{l}\text { A. } \mathrm{ZnO} \mathrm{NPs,} \\
\text { B. } \mathrm{ZnO}: \mathrm{MgO} \mathrm{NPs} \\
\text { C. } \mathrm{ZnO}: \mathrm{Mg}(\mathrm{OH})_{2} \\
\text { composite }\end{array}$ & $\begin{array}{l}\text { A. TEM: } 22-37 \mathrm{~nm} \\
\text { B. TEM: } 23-30 \mathrm{~nm} \\
\text { C. TEM: } 23-49 \mathrm{~nm}\end{array}$ & $\begin{array}{l}\text { Serial dilution } \\
\text { ranging from } 5 \text { to } \\
0.002 \mathrm{mg} \mathrm{mL}^{-1}\end{array}$ & $\begin{array}{l}\text { In vitro assay } \\
\text { (broth microdilution and } \\
\text { agar-media based poison } \\
\text { food technique) }\end{array}$ & $\begin{array}{l}\text { DMSO dissolved NPs } \\
\text { were diluted with PDB in } \\
\text { a geometric progression }\end{array}$ & $\begin{array}{c}\text { Aqueous spore } \\
\text { suspension }\left(1 \times 10^{6}\right. \\
\left.\text { conidia mL } \mathrm{m}^{-1}\right) \text { added } \\
\text { in PDB }\end{array}$ & $\begin{array}{l}\text { Colletotrichum } \\
\text { gloeosporioides }\end{array}$ & $\begin{array}{l}\text {-ZnO NPs alone } \\
\text { exhibited highest } \\
\text { inhibition of the } \\
\text { hyphal growth } \\
\text {-Addition of } \mathrm{MgO} \\
\text { diminished the } \\
\text { antifungal potential } \\
\text { of ZnO NPs }\end{array}$ & [56] \\
\hline $\mathrm{ZnONPs}$ & $\begin{array}{l}\text { TEM: } 20 \mathrm{~nm} \\
\text { (spherical), } 37 \mathrm{~nm} \\
\text { (acicular) }\end{array}$ & $\begin{array}{l}3,6,9 \\
\text { and } 12 \mathrm{mM} \mathrm{L}^{-1}\end{array}$ & $\begin{array}{c}\text { In vitro assay } \\
\text { (poison food technique) }\end{array}$ & $\begin{array}{l}\text { Supplementation of PDA } \\
\text { with different working } \\
\text { concentrations of NPs }\end{array}$ & $\begin{array}{l}\text { Mycelial plug }(1.5 \mathrm{~cm} \\
\text { diameter) from } 16-\text { day } \\
\text { old fungal culture }\end{array}$ & $\begin{array}{l}\text { Erythricium } \\
\text { salmonicolor }\end{array}$ & $\begin{array}{c}\text {-substantial mycelial } \\
\text { growth inhibition at } \\
6 \mathrm{mmol} \mathrm{L}^{-1}\end{array}$ & [68] \\
\hline
\end{tabular}


Table 1. Cont

\begin{tabular}{|c|c|c|c|c|c|c|c|c|}
\hline $\begin{array}{c}\text { Type of } \\
\text { Zn-Nanomaterial Used }\end{array}$ & $\begin{array}{l}\text { Zn-Nanomaterial } \\
\text { Characterization }\end{array}$ & $\begin{array}{c}\text { Working } \\
\text { Concentration }\end{array}$ & $\begin{array}{c}\text { Study Conditions } \\
\text { (Exposure Technique) }\end{array}$ & $\begin{array}{c}\text { Zn-Nanomaterial } \\
\text { Application Method }\end{array}$ & $\begin{array}{c}\text { Pathogen Inoculation } \\
\text { Technique }\end{array}$ & Pathogen Studied & Impact & References \\
\hline $\mathrm{ZnONPs}$ & $\begin{array}{l}\text { Commercial } \\
\text { formulation } \\
\text { (size }<100 \mathrm{~nm} \text { ) }\end{array}$ & $\begin{array}{l}\text { 0, 100, 250, } \\
\text { and } 500 \mathrm{mg}[\mathrm{Zn}] \mathrm{L}^{-1}\end{array}$ & $\begin{array}{c}\text { In vitro assay } \\
\text { (poison food technique) }\end{array}$ & $\begin{array}{l}\text { Different concentrations } \\
\text { of } Z n O N P s \\
\text { supplemented in mung } \\
\text { bean agar media }\end{array}$ & $\begin{array}{l}\text { Mycelial plugs } \\
(\sim 0.5 \times 1.0 \mathrm{~cm}) \text { cut from } \\
\text { the margins of the } 5 \text {-day } \\
\text { old fungal growth }\end{array}$ & Fusarium graminearum & $\begin{array}{l}\text {-dose-dependent } \\
\text { inhibition of fungal } \\
\text { growth }\end{array}$ & [146] \\
\hline $\mathrm{ZnONPs}$ & $\begin{array}{l}\text { TEM: } 30-40 \mathrm{~nm} \\
\text { SEM: triangular- to } \\
\text { hexagonal-shaped } \\
\text { particles } \\
\text { XRD: crystallite } \\
\text { size- } 35.69 \mathrm{~nm}\end{array}$ & $\begin{array}{l}25,50,75,100,125 \\
\text { and } 140 \mu \mathrm{g} \mathrm{mL} \\
-1\end{array}$ & $\begin{array}{l}\text { In vitro assay } \\
\text { (broth culture } \\
\text { experiment) }\end{array}$ & $\begin{array}{l}\text { Different concentrations } \\
\text { of } Z \text { ZnO NPs } \\
\text { supplemented in Czapek } \\
\text { Dox broth }\end{array}$ & $\begin{array}{l}\text { Spore suspension }(10 \mu \mathrm{L} \text {, } \\
10^{6} \text { spores } \mathrm{mL}^{-1} \text { in } \\
\text { peptone water }+0.01 \% \\
\text { Tween } 80) \text { in Czapek Dox } \\
\text { broth }(100 \mathrm{~mL})\end{array}$ & Fusarium graminearum & $\begin{array}{c}\text { In dose-dependent } \\
\text { manner } \\
\text {-ROS accumulation in } \\
\text { treated mycelial } \\
\text {-reduction in } \\
\text { deoxynivalenol and } \\
\text { zearalenone } \\
\text { production }\end{array}$ & [170] \\
\hline $\mathrm{ZnONPs}$ & $\begin{array}{c}\text { TEM: } \\
\text { spherical-shaped } \\
30 \mathrm{~nm} \text { size NPs } \\
\text { XRD: wurtzite } \\
\text { crystal nature }\end{array}$ & $\begin{array}{l}10,25,50, \\
\text { and } 100 \mathrm{mM}\end{array}$ & $\begin{array}{c}\text { In vitro assay } \\
\text { (poison food technique) }\end{array}$ & $\begin{array}{l}\text {-Variable concentrations } \\
\text { added to PDA } \\
\text {-Highest Zn-compounds } \\
\text { concentration added } \\
\text { to PDA }\end{array}$ & $\begin{array}{l}\text { Mycelial disc }(6 \mathrm{~mm}) \\
\text { obtained from } 7 \text {-day-old } \\
\text { fungal cultures from edge }\end{array}$ & $\begin{array}{l}\text { Fusarium graminearum, } \\
\text { Aspergillus flavus, } \\
\text { Penicillium citrinum }\end{array}$ & $\begin{array}{l}\text {-concentration-dependent } \\
\text { decrease in hyphal } \\
\text { growth } \\
\text {-significant decrease } \\
\text { in deoxynivalenol } \\
\text { and aflatoxin B1 only } \\
\text { by ZnO NPs } \\
\text { compared to control }\end{array}$ & [173] \\
\hline $\mathrm{ZnONPs}$ & $\begin{array}{c}\text { DLS: } \\
111.53 \pm 1.3 \mathrm{~nm} \\
\text { TEM: }<100 \mathrm{~nm} \\
\zeta \text {-potential: } \\
-15.89 \mathrm{mV}\end{array}$ & $100-800 \mathrm{ppm}$ & $\begin{array}{c}\text { In vitro assay } \\
\text { (poison food technique) }\end{array}$ & $\begin{array}{l}\text {-Different concentrations } \\
\text { of ZnO NPs added to } \\
\text { Czapek Dox agar }\end{array}$ & $\begin{array}{l}\text { Mycelial disc (5 mm } \\
\text { diameter) was cut from } \\
\text { 5-day old culture }\end{array}$ & Fusarium moniliforme & $\begin{array}{l}\text {-Less hyphal growth } \\
\text { inhibition due larger } \\
\text { sized particles }\end{array}$ & [40] \\
\hline $\mathrm{ZnONPs}$ & $\begin{array}{c}\text { Commercial } \\
\text { formulation } \\
\text { (size: } 70 \pm 15 \mathrm{~nm} \text { ) }\end{array}$ & $\begin{array}{c}0,2,4,6,8 \\
\text { and } 12 \mathrm{mg} \mathrm{L}^{-1}\end{array}$ & $\begin{array}{c}\text { In vitro assay } \\
\text { (poison food technique) }\end{array}$ & $\begin{array}{l}\text { Different concentrations } \\
\text { of ZnO NPs with } \\
\text { autoclaved PD agar } \\
\text { medium }\end{array}$ & $\begin{array}{l}\text { Fungal mycelia plug } \\
\text { ( } 1 \mathrm{~cm} \text { diameter) taken } \\
\text { from the edge of } \\
\text { one-week old culture }\end{array}$ & Fusarium oxysporum & $\begin{array}{l}\text {-19.3-77.5\% hyphal } \\
\text { growth inhibition } \\
\text { corresponding to for } \\
2-12 \mathrm{mg} \mathrm{L}^{-1} \mathrm{ZnO} \mathrm{NP} \\
\text { concentration }\end{array}$ & [66] \\
\hline $\mathrm{ZnONPs}$ & $\begin{array}{c}\text { Commercial } \\
\text { formulation } \\
\text { (spherical-shaped } \\
20-30 \pm 10 \mathrm{~nm} \mathrm{NPs} \text { ) }\end{array}$ & 25,50 , and $100 \mathrm{ppm}$ & $\begin{array}{c}\text { In vitro assay } \\
\text { (poison food technique) }\end{array}$ & $\begin{array}{c}\text { Working concentrations } \\
\text { of ZnO NPs derived from } \\
1000 \text { ppm stock solution } \\
\text { added to sterilized PDA } \\
\text { medium }\end{array}$ & $\begin{array}{l}\text { Fungal disc }(0.5 \mathrm{~cm} \\
\text { diameter) obtained from } \\
\text { 7-old culture }\end{array}$ & $\begin{array}{l}\text { Fusarium oxysporum } f \text {. } \\
\text { sp. betae }\end{array}$ & $\begin{array}{l}-49.3 \% \text { inhibition of } \\
\text { radial hyphal growth } \\
\text { at } 100 \mathrm{ppm}\end{array}$ & [147] \\
\hline $\mathrm{ZnONPs}$ & $\begin{array}{l}\text { Commercial } \\
\text { formulation } \\
\text { (size: }<50 \mathrm{~nm} \text { ) }\end{array}$ & $\begin{array}{l}0-15 \mathrm{mM} \text { equivalent } \\
\text { to } 0-1221 \mathrm{ppm}\end{array}$ & $\begin{array}{c}\text { In vitro assay } \\
\text { (automated turbidimetric } \\
\text { assay) }\end{array}$ & $\begin{array}{c}\text { ZnO NPs } \\
\text { suspension-soaked filter } \\
\text { papers }\end{array}$ & $\begin{array}{c}\text { Spore suspension } \\
\left(1.73 \times 10^{3} \text { conidia } \mathrm{mL}^{-1}\right) \\
\text { were serially diluted }\end{array}$ & Penicillium expansum & $\begin{array}{c}\text {-MIC: } 9.8 \mathrm{mM} \\
\text { (798 ppm) and NIC: } \\
1.8 \mathrm{mM}(147 \mathrm{ppm})\end{array}$ & [148] \\
\hline
\end{tabular}


Table 1. Cont.

\begin{tabular}{|c|c|c|c|c|c|c|c|c|}
\hline $\begin{array}{c}\text { Type of } \\
\text { Zn-Nanomaterial Used }\end{array}$ & $\begin{array}{l}\text { Zn-Nanomaterial } \\
\text { Characterization }\end{array}$ & $\begin{array}{c}\text { Working } \\
\text { Concentration }\end{array}$ & $\begin{array}{c}\text { Study Conditions } \\
\text { (Exposure Technique) }\end{array}$ & $\begin{array}{c}\text { Zn-Nanomaterial } \\
\text { Application Method }\end{array}$ & $\begin{array}{c}\text { Pathogen Inoculation } \\
\text { Technique }\end{array}$ & Pathogen Studied & Impact & References \\
\hline $\begin{array}{l}\text { A. } \mathrm{Zn} \mathrm{NPs} \\
\text { B. ZnO NPs }\end{array}$ & $\begin{array}{c}\text { A. TEM: mean } \\
\text { diameter } 264 \mathrm{~nm} ; \\
\text { hydrodynamic } \\
\text { diameter: } 615.8 \mathrm{~nm} \text {; } \\
\zeta \text {-potential: } \\
-1.6 \pm 3.7 \\
\text { B. TEM: mean } \\
\text { particle diameter } \\
19.3 \mathrm{~nm} ; \\
\text { hydrodynamic } \\
\text { diameter: } 453.3 ; \\
\zeta \text {-potential: } \\
23.3 \pm 5.0\end{array}$ & $0-65 \mathrm{mg} \mathrm{L}^{-1}$ & $\begin{array}{l}\text { In vitro spore } \\
\text { germination and } \\
\text { infectivity tests }\end{array}$ & $\begin{array}{l}\text { Different concentrations } \\
\text { of nano-Zn formulations } \\
\text { incubated with fungal } \\
\text { spore suspension }\end{array}$ & $\begin{array}{c}\text { Spore suspension } \\
\left(10^{6} \text { spores } \mathrm{mL}^{-1}\right) \text { mixed } \\
\text { with DI }\end{array}$ & Peronospora tabacina & $\begin{array}{c}\text {-Inhibition of spore } \\
\text { germination } \\
\text { frequency spore by } \\
\mathrm{Zn} \mathrm{NPs}, \mathrm{ZnONPs}, \\
\text { and } \mathrm{ZnCl} 2(<10 \mathrm{mg} \\
\left.\mathrm{L}^{-1}\right) \\
\text {-Significantly higher } \\
\text { inhibition by } \mathrm{ZnO} \\
\mathrm{NPs} \text { compared to } \\
\text { bulk } \mathrm{ZnO} \\
\text {-Reduction in leaf } \\
\text { infection in tobacco } \\
\text { leaf assay }\end{array}$ & [141] \\
\hline $\mathrm{ZnO}$ and $\mathrm{CuO}$ NPs & $\begin{array}{l}\text { Commercial } \\
\text { formulation }\end{array}$ & $\begin{array}{l}50,100,250 \\
\text { and } 500 \mathrm{mg} \mathrm{L}^{-1}\end{array}$ & $\begin{array}{c}\text { In vitro assay } \\
\text { (poison food technique) }\end{array}$ & $\begin{array}{l}\text { Different concentrations } \\
\text { of NPs amended in } \\
\text { autoclaved PDA media }\end{array}$ & $\begin{array}{l}\text { Fungal growth plug } \\
\left(0.5 \mathrm{~cm}^{2}\right) \text { placed in center } \\
\text { of PDA media }\end{array}$ & $\begin{array}{c}\text { Pythium ultimum, } \\
\text { Pythium } \\
\text { aphanidermatum }\end{array}$ & $\begin{array}{l}\text {-Inhibition of growth } \\
\text { at low concentrations } \\
\text {-morphological } \\
\text { changes in the hyphae }\end{array}$ & [142] \\
\hline \multicolumn{9}{|c|}{ Viral pathogens } \\
\hline $\mathrm{ZnONPs}$ & $\begin{array}{l}\text { TEM: } 18 \mathrm{~nm} \\
\text { spherical-shaped } \\
\text { particles }\end{array}$ & $\begin{array}{l}\text { A. } 100 \mu \mathrm{g} \mathrm{mL}^{-1} \\
\text { B. } 100 \mu \mathrm{g} \mathrm{mL} \mathrm{m}^{-1} \\
\text { (5L } \mathrm{mP} \text { solution } \\
\text { foliar spray for } 3,7, \\
\text { and } 12 \text { days) }\end{array}$ & $\begin{array}{l}\text { A. In vitro assay } \\
\text { B. In planta assay } \\
\text { (Nicotiana benthamiana) }\end{array}$ & $\begin{array}{c}\text { A. ZnO NP suspension } \\
\text { mixed with purified TMV } \\
\text { particles } \\
\text { B. Foliar spray of NPs } \\
\text { suspensions }\end{array}$ & $\begin{array}{l}\text { A. Purified TMV particles } \\
\text { mixed with NPs } \\
\text { B. Inoculation by rubbing } \\
\text { infected leaves onto the } \\
\text { oldest leaf }\end{array}$ & Tobacco mosaic virus & $\begin{array}{l}\text { A. aggregation or } \\
\text { breakage of tobacco } \\
\text { mosaic virus particles } \\
\text { B. marked } \\
\text { suppression }(35.33 \%) \\
\text { of TMV invasion in } \\
\text { the inoculated leaves }\end{array}$ & [45] \\
\hline
\end{tabular}




\section{Zinc Nanoformulations: In Planta Studies and Crop Plant Responses to Pathogen Attacks}

Zinc nanoformulations have been evaluated to curb phytopathogenic infections in various crop plants. The major test crop plants that have been utilized as models to evaluate the antimicrobial potential of the nanozinc products include tomato [67], tobacco [141], pepper [145], rice, and wheat [174]. The antibacterial potential of ZnO NPs against Pseudomonas syringae pv. tomato DC3000 that causes bacterial speck disease in tomato [67] has been reported. In planta greenhouse study performed with Lycopersicon esculentum cv. Pantelosa transplants involved foliar spray treatment of $\mathrm{ZnO}$ NPs $\left(100 \mu \mathrm{g} \mathrm{mL}^{-1}\right)$ at a five-leaf stage, which significantly reduced the disease severity as compared to untreated control post-1 week of inoculation of the bacterial pathogen. Further, the researchers also indicated elicitation of the plant's innate defense system through physiological and biochemical studies including antioxidant enzyme activities and profound vegetative growth [67]. Another interesting study involving the effect of ZnO NPs on synthesis and secretion of signal compounds (siderophores-pyoverdine) by plant growth-promoting rhizobacteria-Pseudomonas chlororaphis O6 improved the lateral root formation in wheat plants besides enhancing the immunity of the treated plants [174]. The use of $\mathrm{ZnO}$ quantum dots (QDs) surface-functionalized with kasugamycin antibiotic has been evaluated for on-demand $\mathrm{pH}$-responsive release of the loaded antibiotic in a greenhouse study to effectively control Acidovorax citrulli and alleviate the disease severity symptoms of bacterial fruit blotch in watermelon seedlings [175].

The mixed formulation developed as zinc/copper nanocomposites have also been evaluated for their antimicrobial efficacy under field conditions. Suppression of disease symptoms caused by the Citrus canker causative agent, Xanthomonas citri subsp. citri were investigated under field conditions on the application of a $\mathrm{ZnO}$-nanoCu-loaded silica gel ( $\mathrm{ZnO}-\mathrm{nCuSiO}{ }_{2}$ composite) nanocomposite. Young et al. [176] investigated the $\mathrm{ZnO}-\mathrm{nCuSi}$ for controlling citrus canker disease under field conditions and found that this was effective in suppressing disease at less than half the metallic rate of the commercial cuprous oxide/zinc oxide pesticide, and no phytotoxicity was observed.

Antifungal activities of $\mathrm{ZnO}$ NPs biosynthesized from leaf extracts of Olea europaea and Origanum majorana plants were evaluated. These NPs significantly reduced the appearance of gray and black mold disease symptoms on artificial inoculation with Botrytis cinerea and Alternaria alternata in test pepper plants compared to chemically synthesized ZnONPs and untreated control plants [145]. Likewise, a comparative in vivo efficacy study for suppression of Botrytis cinerea causing gray mold disease on plum fruits (Prunus domestica) by treatment with $\mathrm{Ag}$, $\mathrm{Cu}$, and $\mathrm{ZnO}$ NPs at two different concentrations (100 and $1000 \mu \mathrm{g} \mathrm{mL}^{-1}$ ) was performed [59]. The researchers observed complete inhibition of disease symptoms by AgNPs only while $\mathrm{ZnO}$ and CuNPs could help control disease symptoms numerically higher or equivalent to copper hydroxide treatment. A simulation study conducted by Wagner et al. [136] on tobacco leaves revealed the high antifungal potential of $\mathrm{Zn}$ nanomaterial against Peronospora tabacina primarily through inhibition of the spore germination process. An interactive protective effect of nano- $\mathrm{ZnO}$ particle seedling spray/seed soaking followed by seedling spray treatments along with the biocontrol agent, Trichoderma harzianum, improved plant's resistance against the causative agent of damping-off disease (Rhizoctonia solani) in sunflower seedlings [177].

Zinc nanomaterials also possess elaborate antiviral properties though the reports on in planta studies involving management of the plant viral diseases are recent and incipient. Hence, little literature is available on this aspect. An in vivo experiment on Nicotiana benthamiana involved marked inhibition of replication of the Tobacco mosaic virus on foliar spray treatment of ZnO NPs for approximately 2 weeks (12 days). The replication inhibition process may be attributed to improved growth and induction of plant defense responses as indicated by an escalation in accumulation of ROS, and activity of the ROS mitigating enzyme besides upregulation of pathogenesis resistance-related genes [45]. 


\section{Zinc-Derived Nanomaterials for the Development of Tools/Devices for Plant Disease Diagnosis}

Pathogenic disorders or diseases in plants can be identified through various imaging, spectroscopy, and conjugate imaging and spectroscopy techniques [178]. Most likely, the role of diagnostic techniques is to achieve quick, early, sensitive, simple, in situ, reliable, and automated high throughput identification and quantification of the causative agent so that the extent of virulence can be obtained before the appearance of the actual visual symptoms of the disease [179]. Nanomaterial-based sensor technologies provide flexible and diverse sensing platforms or methods for elucidation/quantification of the single or multiple analytes [180] and can help ensure early, rapid, and sensitive identification of the plant pathogen [181].

The plant produces a myriad of signal molecules in response to a pathogen attack. Few abundant and signature signal molecules including specific enzymes, gaseous molecules (e.g., nitrous oxide, volatile organic compounds), reactive oxygen species, secretory compounds such as oxylipins and expression of a crucial gene (pathogenesis-related proteins-PRPs, PAMPs) can be aptly utilized as key biomarkers for the development of nanobiosensor platforms [178]. As discussed in Section 3.2.2., several mycotoxigenic fungi produce diffusible exotoxins, which can also be utilized as markers for the identification and confirmation of phytopathogenic fungi. A nano-ZnO film-indium-tin oxide electrochemical impedance sensor was developed by coimmobilization of antibodies and BSA protein to detect ochratoxin-A in produce and other plant-derived products [182]. Likewise, DNA aptamer-functionalized $\mathrm{ZnO} / \mathrm{ZnS}$ quantum dots can help in easy detection of plant pathogens [181].

Sensors systems based on zinc nanomaterials primarily include the semiconductor quantum dot (core-shell, CdSe/CdTe core ZnS shell QDs, and ZnTe or ZnSe QDs)-enabled optical (fluorescence-based) sensors [183]. High luminescence QDs are fascinating nanomaterials that can be used to develop protein-protein/protein-ligand detection assays including the fluorescence resonance energy transfer technique [184]. In fixed cell systems, the QDs can be extensively used as immunohistochemical labels [185].

The protein —antibody immunofluorescence-based biosensors are finding sensing applications for plant virus pathogens [186]. Medintz et al. [187] have developed a CdTe/ZnS core-shell QD-based sensor by labelling NeutrAvidin on the surface of biotinylated Cowpea mosaic virus (CPMV) and avidin-decorated QDs, which interacted through the biotin-avidin groups. Further, CdTe/ZnSe core-shell QDs can also be utilized for easy detection of DNA sequence change mutation events [188]. The nano-Zn-based QDs exhibit low cytotoxicity and produce high-intensity fluorescence signals, which have resolutions far beyond the diffraction limit of light [183]. Therefore, these can also be utilized for in planta or in vivo assays. Early and sensitive detection (detection limit of $25 \mu \mathrm{g} \mathrm{mL}^{-1}$ ) of plant pathogenic Fusarium oxysporum has been reported through the use of 3-Mercaptopropionic acid-functionalized CdSe/ZnS QD in a fluorescence-based assay [189].

Other than fluorescence-based sensors, nano-Zn enabled optical biosensors have also been developed. One of the most promising applications of these nano-Zn-enabled optical biosensors is quick and sensitive detection of plant pathogenic viruses. A sensitive immune-optical biosensor was developed, which involved immobilization of antibodies against Grapevine virus A-type (GVA) antigenic proteins on a $\mathrm{ZnO}$ thin film prepared by the atomic layer deposition technique [190].

As zinc nanomaterials exhibit electron-hole generation due to their semiconductor behavior; these have also been used to develop another category of a sensor system, the electrochemical sensors. Zinc oxide nanorod cyclic voltammetry-based electrochemical sensor has been developed as a disposable sensor for a rapid, cost-effective, and label-free detection of E. coli in food matrices [191]. Tahir et al. [192] have investigated the potential of a ZnO-nanocomposite prepared by decorating zinc nanoparticles $(25-500 \mathrm{~nm}$ ) on the surface of multiwall carbon nanotubes to immobilize probe DNA strands having complementarity to Chili leaf curl virus beta satellite. They have assessed the electrochemical performance of this DNA biosensor through the binding of the DNA by cyclic and 
differential pulse voltammetry scans. A similar kind of electrochemical DNA biosensor has been reported to be developed involving $\mathrm{ZnO}$ nanoparticles-chitosan membrane-doped gold electrode to conveniently identify Trichoderma harzianum biocontrol fungus [193].

\section{Potential Application of Zn-Based Nanomaterials and Future Use}

Zinc nanomaterials have found elaborate applications in diverse fields of agrirelevance such as for fertilizer nutrient delivery [194] through foliar application [195] or sustained release of nutrient from a nanodelivery vehicle [196,197], as novel antimicrobial agent $[40,198,199]$, pesticide [200], and for environmental remediation [201-203]. The role of zinc nanomaterials in nanodiagnostics has been already dealt with in Section 5. Several reports delineating the role of zinc nanomaterials for elicitation of the systemic acquired immunity (SAR) in plants to combat and curb attack by various phytopathogens have been indicating towards the gross positive impact of their use in plant crops [204]. The specific aspects that need to be delved on regarding the voluminous and wide-spread usage of zinc nanomaterials for management of phytopathogens include the development of stable nanozinc formulations and their environmental impacts in the soil food-web on nontarget organisms.

\subsection{Ecosafety Issues of Nanozinc-Derived Products and Devices}

Agriculture is a pivotal global enterprise thrusting the economies of most of nations. Therefore, the products or chemicals utilized for improving the nutritional status (fertilizers) $[194,196,197]$ and for management of the plant pathogenic infections (pesticides) are anticipated to be utilized in quantum amounts. Therefore, a cautious and critical approach is desirable considering the atypical behavior in open, dynamic, and complex multicomponent systems. Further, the ecological nanotoxicity concerns of these materials need to be identified before approving the use of zinc nanomaterial-based agriproducts [205-207].

A pride and prejudice dilemma exists as zinc nanomaterials, particularly the ZnO NPs, are being exponentially synthesized due to amenability for easy and low-cost production processes [208,209]. Further, the functional versatility of nanomaterials renders them affordable for applications or use in diverse fields spanning over electronics, biomedicine [17,18], environment remediation [210], catalysis [211], agriculture [40], and cosmetics industries. However, the release of $\mathrm{Zn}$ nanomaterial through municipal wastewater/sewage water, industrial effluent, and surface wash water drifts these nanomaterials to contaminate diverse soil and water ecosystems posing gradual and subtle to drastic effects on soil and aquatic biota thereby exacerbating the health and sanctity of the contaminated eco-niches [212]. The semiconductor (oxidative stress-inducing) properties and heavy metal nature of the zinc nanomaterials (bioaccumulation) further complicate their ecotoxicity concerns [213] besides the fundamental nanoscale aspects (quantum size effects-size, shape, surface charge-dependent properties, and agglomeration/complexation processes), which lead to diverse cyto-/genotoxic and onco-/mutagenic effects [214]. The nano- $\mathrm{Zn}$ material and their dissolution product, i.e., $\mathrm{Zn}^{2+}$ ions exhibit toxicity to all types of organisms or biotic components of all trophic levels [215]. Further, the occurrence of other pollutants may enhance the pernicious effects of nano-Zn-based products [214]. Therefore, long-term field studies need to be designed besides improvement in the in silico simulation modeling studies to well predict the aftermaths of the rampant use of nano-Zn-based products in agriculture.

\subsection{Improved Nanozinc Formulations: The Scar and Sanctity of Stability and Biosafety}

Zinc nanomaterials can be synthesized using physical and chemical techniques [216]. However, several reports have considered the biologically synthesized nanozinc formulations to be cost-effective, ecosafe, and stable even under ambient storage conditions [217]. Further, higher antimicrobial efficacy and improved photocatalytic activity were reported for the zinc oxide nanoparticles synthesized from the neem leaf extracts [217]. Although the researchers reported a slight difference in the mean size of the ZnO NPs (sol-gel: $33.20 \mathrm{~nm}$ and biosynthesized: $25.97 \mathrm{~nm}$ ), they have argued that the improved 
efficacy of the neem extract-derived ZnO NPs was due to greater stability of the dispersion owing to surface functionalization by the leaf phenolics or terpenoids.

The stability of nanozinc formulations is governed by size-dependent phenomena. Further, the zeta potential and the surface charge ensure the aggregation, flocculation, or sedimentation of the nanoparticles [218]. Most likely, the zinc nanoformulations are made stable by altering either the charge (charge-stabilized dispersions) or the steric hindrance (sterically stabilized dispersions). The former mechanism slows down the rate of aggregation of the nanoparticles due to electrostatic repulsion forces [219], whereas the latter involves grafting of polymer coating due to the addition of polymers acting as steric stabilizers (e.g., polyvinyl pyrrolidone, polysorbate 80 , polyethylene glycol, and many more) on the surface of the dispersed nanoparticles inducing thermodynamic stability $[220,221]$. However, the surface charge of the $\mathrm{ZnO}$ nanomaterial suspensions also decide for the eco- and cytotoxicity of these nanomaterials [222]. The nano- $\mathrm{ZnO}$ particle dispersion bearing positive charge at cell physiological $\mathrm{pH}$ exhibits an enhanced ability to penetrate the cells than the vice versa [223].

\section{Conclusions}

The nano-Zn products, particularly the nanoformulations developed for suppression of bacterial, phytoplasma, fungal, or viral diseases in crop plants, can have a gross impact on decreasing the extent of voluminous use of conventional metal(s)-based pesticides. These formulations can be designed for the management of diseases in both open field and closed greenhouse/screen-house conditions and can be applied to crop plants through several application modes. The prior research has shown high effectivity of nano-Zn formulations to curb phytopathogen owing to versatile antimicrobial mechanism of action including photo-oxidation leading to generation of reactive oxygen species, destabilization of the cell membrane, organelles, and other cellular macromolecules, and toxicity due to the release of zinc ions. The zinc nanomaterials have also been utilized for the development of affordable sensor systems for sensitive and early detection of pathogen attack that can be used for predicting the crop losses and for surveillance purposes. Although there are apparent advantages of the use of zinc nanomaterials for diverse benefits, however, their proficient use is limited due to rising concerns about ecohealth deterring aspects of nanomaterials and the bio-/econanotoxicity issues that need to be addressed. The problems such as bioaccumulation across the food chain and food web, complexities of events and components of the plant-soil-atmosphere-pathogen continuum, photo-oxidation properties, and the unprecedented fate of applied nanomaterials in the environment depreciate, comprise, or even negate the advantages of zinc nanomaterials as novel plant disease suppression or eradication agents. Carefully designed protocols and assays dissecting the dimensions and role of nanoscale particles/materials on pathogen and plant can improve our know-how and may direct novel paradigms for adaptation and application of zinc nanomaterials to overt the global food production challenges posed by phytopathogens.

Author Contributions: Conceptualization, A.K.; writing—original draft preparation, A.K.; writing-review and editing, K.A.A.-E. and K.K.; visualization, A.K.; funding acquisition, A.K. and K.K. All authors have read and agreed to the published version of the manuscript.

Funding: This research was funded by Rashtriya Krishi Vikas Yojana (RKVY) scheme, Government of India. It was also supported by UHK (VT2019-2021).

Acknowledgments: A.K. thanks the Head, Department of Soil Science, CoA, for providing the necessary infrastructural facilities and the Director of Research, Punjab Agricultural University, Ludhiana, Punjab, for allocation of funds through RKVY scheme.

Conflicts of Interest: The authors declare no conflict of interest. The funders had no role in the design of the study; in the collection, analyses, or interpretation of data; in the writing of the manuscript, or in the decision to publish the results. 


\section{References}

1. Savary, S.; Willocquet, L.; Pethybridge, S.J.; Esker, P.; McRoberts, N.; Nelson, A. The global burden of pathogens and pests on major food crops. Nat. Ecol. Evol. 2019, 3, 430-439. [CrossRef]

2. FAO. The State of Food and Agriculture 2019. In Moving Forward on Food Loss and Waste Reduction; FAO: Rome, Italy, 2019.

3. Rajasekaran, P.; Kannan, H.; Das, S.; Young, M.; Santra, S. Comparative analysis of copper and zinc-based agrichemical biocide products: Materials characteristics, phytotoxicity and in vitro antimicrobial efficacy. AIMS Environ. Sci. 2016, 3, 439-455. [CrossRef]

4. U.S. EPA/OPPTS (Environmental Protection Agency- Office of Prevention, Pesticides and Toxic Substances). Reregistration Eligibility Decision (R.E.D.) Facts-Zinc Salts. EPA 738-R-98-007, 1992, Washington, DC, U.S. Available online: https://archive.epa.gov/pesticides/reregistration/web/pdf/zinc_salt.pdf (accessed on 12 October 2020).

5. Curry, A.S.; Price, D.E.; Tryhorn, F.G. Absorption of zinc phosphide particles. Nature 1959, 184, $642-643$. [CrossRef]

6. Hood, G.A. Zinc Phosphide-A new look at an old rodenticide for field rodents. In Proceedings of the 5th Vertebrate Pest Conference, Fresno, CA, USA, 7-9 March 1972; Volume 5, pp. 85-92.

7. US-EPA. Zinc oxide: Exemption from the requirement of a tolerance. Fed. Regist. 2018, 83, 42783-42787. Available online: https://www.govinfo.gov/content/pkg/FR-2018-08-24/pdf/2018-18402.pdf (accessed on 12 October 2020).

8. Almoudi, M.M.; Hussein, A.S.; Abu Hassan, M.I.; Mohamad Zain, N. A systematic review on antibacterial activity of zinc against Streptococcus mutans. Saudi Dent. J. 2018, 30, 283-291. [CrossRef]

9. Burgess, J.; Prince, R.H. Zinc: Inorganic \& Coordination Chemistry. In Encyclopedia of Inorganic Chemistry, 1st ed.; King, R.B., Ed.; John Wiley \& Sons, Ltd., Wiley: Hoboken, NJ, USA, 2006; pp. 1-26.

10. Dos Santos, R.A.A.; D'Addazio, V.; Silva, J.V.G.; Falqueto, A.R.; Barreto da Silva, M.; Schmildt, E.R.; Fernandes, A.A. Antifungal Activity of Copper, Zinc and Potassium Compounds on Mycelial Growth and Conidial Germination of Fusarium solani f. sp. piperis. Microbiol. Res. J. Int. 2019, 29, 1-11. [CrossRef]

11. Goodwin, F.E. Zinc Compounds. In Kirk-Othmer Encycl. Chem. Technol.; Kroschwitz, J., Howe-Grant, M., Eds.; John Wiley \& Sons, Inc.: New York, NY, USA, 1998; pp. 840-853.

12. Qureshi, S.A.; Shafeeq, A.; Ijaz, A.; Butt, M.M. Development of algae guard façade paint with statistical modeling under natural phenomena. Coatings 2018, 8, 440. [CrossRef]

13. Gupta, S.; Sharma, D.; Gupta, M. Climate change impact on plant diseases: Opinion, trends and mitigation strategies. In Microbes for Climate Resilient Agriculture; Kashyap, P.L., Srivastava, A.K., Tiwari, S.P., Kumar, S., Eds.; John Wiley \& Sons, Inc.: Hoboken, NJ, USA, 2018; pp. 41-56.

14. Luck, J.; Asaduzzaman, M.; Banerjee, S.; Bhattacharya, I.; Coughlan, K.; Debnath, G.; De Boer, D.; Dutta, S.; Forbes, G.; Griffiths, W.; et al. The Effects of Climate Change on Pests and Diseases of Major Food Crops in the Asia Pacific Region; Final Report for APN Project (Project Reference: ARCP2010-05CMY-Luck); Asia Pacific Network for Global Change Research: Kobe, Japan, 2010.

15. Lurwanu, Y.; Wang, Y.P.; Abdul, W.; Zhan, J.; Yang, L.N. Temperature-mediated plasticity regulates the adaptation of Phytophthora infestans to azoxystrobin fungicide. Sustainability 2020, 12, 1188. [CrossRef]

16. Ishii, H. Impact of fungicide resistance in plant pathogens on crop disease control and agricultural environment. Jpn. Agric. Res. Q. 2006, 40, 205-211. [CrossRef]

17. Kalia, A.; Manchanda, P.; Bhardwaj, S.; Singh, G. Biosynthesized silver nanoparticles from aqueous extracts of sweet lime fruit and callus tissues possess variable antioxidant and antimicrobial potentials. Inorg. Nano-Metal Chem. 2020, 50, 1053-1062. [CrossRef]

18. Kaur, G.; Kalia, A.; Sodhi, H.S. Size controlled, time-efficient biosynthesis of silver nanoparticles from Pleurotus florida using ultra-violet, visible range, and microwave radiations. Inorg. Nano-Metal Chem. 2020, 50, 35-41. [CrossRef]

19. Munir, M.U.; Ihsan, A.; Javed, I.; Ansari, M.T.; Bajwa, S.Z.; Bukhari, S.N.A.; Ahmed, A.; Malik, M.Z.; Khan, W.S. Controllably biodegradable hydroxyapatite nanostructures for cefazolin delivery against antibacterial resistance. ACS Omega 2019, 4, 7524-7532. [CrossRef]

20. Kalainila, P.; Ravindran, R.S.E.; Rohit, R.; Renganathan, S. Anti-bacterial effect of biosynthesized silver nanoparticles using Kigelia africana. J. Nanosci. Nanoengn. 2015, 1, 225-232. 
21. Jangra, S.L.; Stalin, K.; Dilbaghi, N.; Kumar, S.; Tawale, J.; Singh, S.P.; Pasricha, R. Antimicrobial activity of zirconia $\left(\mathrm{ZrO}_{2}\right)$ nanoparticles and zirconium complexes. J. Nanosci. Nanotechnol. 2012, 12, 7105-7112. [CrossRef]

22. Satyavani, K.; Gurudeeban, S.; Ramanathan, T.; Balasubramanian, T. Biomedical potential of silver nanoparticles synthesized from calli cells of Citrullus colocynthis (L.) Schrad. J. Nanobiotechnol. 2011, 9, 43. [CrossRef]

23. Huang, F.; Long, Y.; Liang, Q.; Purushotham, B.; Swamy, M.K.; Duan, Y. Safed Musli (Chlorophytum borivilianum L.) Callus-Mediated Biosynthesis of Silver Nanoparticles and Evaluation of their Antimicrobial Activity and Cytotoxicity against Human Colon Cancer Cells. J. Nanomater. 2019, 1-8. [CrossRef]

24. Azizi, S.; Mohamad, R.; Shahri, M.M.; McPhee, D.J. Green microwave-assisted combustion synthesis of zinc oxide nanoparticles with Citrullus colocynthis (L.) schrad: Characterization and biomedical applications. Molecules 2017, 22, 301. [CrossRef]

25. Sánchez-López, E.; Gomes, D.; Esteruelas, G.; Bonilla, L.; Lopez-Machado, A.L.; Galindo, R.; Cano, A.; Espina, M.; Ettcheto, M.; Camins, A.; et al. Metal-based nanoparticles as antimicrobial agents: An overview. Nanomaterials 2020, 10, 292. [CrossRef]

26. Singh, J.; Vishwakarma, K.; Ramawat, N.; Rai, P.; Singh, V.K.; Mishra, R.K.; Kumar, V.; Tripathi, D.K.; Sharma, S. Nanomaterials and microbes' interactions: A contemporary overview. 3 Biotech 2019, 9, 68. [CrossRef]

27. Díez-Pascual, A.M. Antibacterial activity of nanomaterials. Nanomaterials 2018, 8, 359. [CrossRef]

28. Mostafa, M.; Almoammar, H.; Abd-Elsalam, K.A. Zinc-based nanostructures in plant protection applications. In Nanobiotechnology Applications in Plant Protection, Nanotechnology in the Life Sciences; Abd-Elsalam, K.A., Prasad, R., Eds.; Springer Nature Switzerland AG: Cham, Switzerland, 2019; pp. 49-83. ISBN 9783030132965.

29. Vollath, D. Nanomaterials: An Introduction to Synthesis, Properties, and Applications, 2nd ed.; Wiley-VCH, Verlag GmbH \& Co. KGaA: Weinheim, Germany, 2013; ISBN 9780470927076.

30. Siegel, R. Nanostructured materials. In Advanced Topics in Materials Science and Engineering; Morán-López, J.L., Sanchez, J.M., Eds.; Springer: Boston, MA, USA; New York, NY, USA, 1993; pp. 273-288. ISBN 9788578110796.

31. Murr, L.E. Handbook of materials structures, properties, processing and performance. In Handbook of Materials Structures, Properties, Processing and Performance; Murr, L., Ed.; Springer International Publishing: Cham, Switzerland, 2015; pp. 719-746. ISBN 9783319018157.

32. Khan, I.; Saeed, K.; Khan, I. Nanoparticles: Properties, applications and toxicities. Arab. J. Chem. 2019, 12, 908-931. [CrossRef]

33. Mourdikoudis, S.; Pallares, R.M.; Thanh, N.T.K. Characterization techniques for nanoparticles: Comparison and complementarity upon studying nanoparticle properties. Nanoscale 2018, 10, 12871-12934. [CrossRef]

34. Roduner, E. Physics and Chemistry of Nanostructures: Why nano is different. Encycl. Life Support Syst. 2009, 1-35.

35. Roduner, E. Size matters: Why nanomaterials are different. Chem. Soc. Rev. 2006, 35, 583-592. [CrossRef] [PubMed]

36. de Voorde, M.; Tulinski, M.; Jurczyk, M. Engineered nanomaterials: A discussion of the major categories of nanomaterials. In Metrology and Standardization for Nanotechnology: Protocols and Industrial Innovations; Mansfield, E., Kaiser, M., Fujita, D., de Voorde, M., Eds.; Wiley-VCH, Verlag GmbH \& Co. KgaA: Weinheim, Germany, 2017; pp. 49-73.

37. Christian, P. Nanomaterials: Properties, Preparation and Applications. In Environmental and Human Health Impacts of Nanotechnology; Lead, J.R., Smith, E., Eds.; Wiley-Blackwell Publishing Ltd.: Chichester, UK, 2009; pp. 31-77. ISBN 978-1-405-17634-7.

38. Sun, C.Q. Size dependence of nanostructures: Impact of bond order deficiency. Prog. Solid State Chem. 2007, 35, 1-159. [CrossRef]

39. Andrievskii, R.A. Size-dependent effects in properties of nanostructured materials. Rev. Adv. Mater. Sci. 2009, 21, 107-133.

40. Kalia, A.; Kaur, J.; Kaur, A.; Singh, N. Antimycotic activity of biogenically synthesised metal and metal oxide nanoparticles against plant pathogenic fungus Fusarium moniliforme (F. fujikuroi). Indian J. Exp. Biol. 2020, 58, 263-270. 
41. Khan, M.; Shaik, M.R.; Khan, S.T.; Adil, S.F.; Kuniyil, M.; Khan, M.; Al-Warthan, A.A.; Siddiqui, M.R.H.; Nawaz Tahir, M. Enhanced Antimicrobial Activity of Biofunctionalized Zirconia Nanoparticles. ACS Omega 2020, 5, 1987-1996. [CrossRef]

42. Van Der Wal, A.; Norde, W.; Zehnder, A.J.B.; Lyklema, J. Determination of the total charge in the cell walls of Gram-positive bacteria. Colloids Surf. B Biointerfaces 1997, 9, 81-100. [CrossRef]

43. Chen, M.; Zeng, G.; Xu, P.; Lai, C.; Tang, L. How Do Enzymes 'Meet' Nanoparticles and Nanomaterials? Trends Biochem. Sci. 2017, 42, 914-930. [CrossRef]

44. Kaur, M.; Kalia, A. Role of salt precursors for the synthesis of zinc oxide nanoparticles and in imparting variable antimicrobial activity. J. Appl. Nat. Sci. 2016, 8, 1039-1048. [CrossRef]

45. Cai, L.; Liu, C.; Fan, G.; Liu, C.; Sun, X. Preventing viral disease by ZnONPs through directly deactivating TMV and activating plant immunity in Nicotiana benthamiana. Environ. Sci. Nano 2019, 6, 3653-3669. [CrossRef]

46. Alum, A.; Rashid, A.; Mobasher, B.; Abbaszadegan, M. Cement-based biocide coatings for controlling algal growth in water distribution canals. Cem. Concr. Compos. 2008, 30, 839-847. [CrossRef]

47. Dizaj, S.M.; Lotfipour, F.; Barzegar-Jalali, M.; Zarrintan, M.H.; Adibkia, K. Antimicrobial activity of the metals and metal oxide nanoparticles. Mater. Sci. Eng. C 2014, 44, 278-284. [CrossRef]

48. Raghupathi, K.R.; Koodali, R.T.; Manna, A.C. Size-dependent bacterial growth inhibition and mechanism of antibacterial activity of zinc oxide nanoparticles. Langmuir 2011, 27, 4020-4028. [CrossRef]

49. El-Sayed, A.S.A.; Ali, D.M.I. Biosynthesis and comparative bactericidal activity of silver nanoparticles synthesized by Aspergillus flavus and Penicillium crustosum against the multidrug-resistant bacteria. J. Microbiol. Biotechnol. 2018. [CrossRef]

50. Jamdagni, P.; Rana, J.S.; Khatri, P.; Nehra, K. Comparative account of antifungal activity of green and chemically synthesized Zinc Oxide nanoparticles in combination with agricultural fungicides. Int. J. Nano Dimens. 2018, 9, 198-208.

51. Auyeung, A.; Casillas-Santana, M.Á.; Martínez-Castañón, G.A.; Slavin, Y.N.; Zhao, W.; Asnis, J.; Häfeli, U.O.; Bach, H. Effective control of molds using a combination of nanoparticles. PLoS ONE 2017, 12, 1-13. [CrossRef] [PubMed]

52. Lamsal, K.; Kim, S.W.; Jung, J.H.; Kim, Y.S.; Kim, K.S.; Lee, Y.S. Inhibition effects of silver nanoparticles against powdery mildews on cucumber and pumpkin. Mycobiology 2011, 39, 26-32. [CrossRef] [PubMed]

53. Park, H.-J.; Kim, S.H.; Kim, H.J.; Choi, S.-H. A new composition of nanosized silica-silver for control of various plant diseases. Plant Pathol. J. 2006, 22, 295-302. [CrossRef]

54. Kim, H.; Kang, H.; Chu, G.; Byun, H. Antifungal effectiveness of nanosilver colloid against rose powdery mildew in greenhouses. Solid State Phenom. 2008, 135, 15-18. [CrossRef]

55. Li, J.; Sang, H.; Guo, H.; Popko, J.T.; He, L.; White, J.C.; Parkash Dhankher, O.; Jung, G.; Xing, B. Antifungal mechanisms of $\mathrm{ZnO}$ and Ag nanoparticles to Sclerotinia homoeocarpa. Nanotechnology 2017, 28, 155101. [CrossRef] [PubMed]

56. De La Rosa-García, S.C.; Martínez-Torres, P.; Gómez-Cornelio, S.; Corral-Aguado, M.A.; Quintana, P.; Gómez-Ortíz, N.M. Antifungal activity of $\mathrm{ZnO}$ and $\mathrm{MgO}$ nanomaterials and their mixtures against colletotrichum gloeosporioides strains from tropical fruit. J. Nanomater. 2018, 2018. [CrossRef]

57. Karimiyan, A.; Najafzadeh,H.; Ghorbanpour, M.; Hekmati-Moghaddam, S.H. Antifungal Effect of Magnesium Oxide, Zinc Oxide, Silicon Oxide and Copper Oxide Nanoparticles Against Candida albicans. Zahedan J. Res. Med. Sci. 2015, 17, 2-4. [CrossRef]

58. Roy, A.; Gauri, S.S.; Bhattacharya, M.; Bhattacharya, J. Antimicrobial activity of CaO nanoparticles. J. Biomed. Nanotechnol. 2013, 9, 1570-1578. [CrossRef]

59. Malandrakis, A.A.; Kavroulakis, N.; Chrysikopoulos, C.V. Use of copper, silver and zinc nanoparticles against foliar and soil-borne plant pathogens. Sci. Total Environ. 2019, 670, 292-299. [CrossRef]

60. Choudhary, M.A.; Manan, R.; Aslam Mirza, M.; Rashid Khan, H.; Qayyum, S.; Ahmed, Z. Biogenic Synthesis of Copper oxide and Zinc oxide Nanoparticles and their Application as Antifungal Agents. Int. J. Mater. Sci. Eng. 2018, 4, 1-6. [CrossRef]

61. Hao, Y.; Cao, X.; Ma, C.; Zhang, Z.; Zhao, N.; Ali, A.; Hou, T.; Xiang, Z.; Zhuang, J.; Wu, S.; et al. Potential Applications and Antifungal Activities of Engineered Nanomaterials against Gray Mold Disease Agent Botrytis cinerea on Rose Petals. Front. Plant Sci. 2017, 8, 1-9. [CrossRef] 
62. Al-Dhabaan, F.A.; Shoala, T.; Ali, A.A.; Alaa, M.; Abd-Elsalam, K.; Abd-Elsalam, K. Chemically-produced copper, zinc nanoparticles and chitosan-bimetallic nanocomposites and their antifungal activity against three phytopathogenic fungi. Int. J. Agric. Technol. 2017, 13, 753-769.

63. Vahedi, M.; Hosseini-Jazani, N.; Yousefi, S.; Ghahremani, M. Evaluation of anti-bacterial effects of nickel nanoparticles on biofilm production by Staphylococcus epidermidis. Iran. J. Microbiol. 2017, 9, 160-168.

64. Srihasam, S.; Thyagarajan, K.; Korivi, M.; Lebaka, V.R.; Mallem, S.P.R. Phytogenic generation of NiO nanoparticles using stevia leaf extract and evaluation of their in-vitro antioxidant and antimicrobial properties. Biomolecules 2020, 10. [CrossRef] [PubMed]

65. Bogdan, J.; Zarzyńska, J.; Pławińska-Czarnak, J. Comparison of Infectious Agents Susceptibility to Photocatalytic Effects of Nanosized Titanium and Zinc Oxides: A Practical Approach. Nanoscale Res. Lett. 2015, 10. [CrossRef]

66. Yehia, R.; Ahmed, O.F. In vitro study of the antifungal efficacy of zinc oxide nanoparticles against Fusarium oxysporum and Penicilium expansum. Afr. J. Microbiol. Res. 2013, 7, 1917-1923. [CrossRef]

67. Elsharkawy, M.; Derbalah, A.; Hamza, A.; El-Shaer, A. Zinc oxide nanostructures as a control strategy of bacterial speck of tomato caused by Pseudomonas syringae in Egypt. Environ. Sci. Pollut. Res. 2018, 27, 19049-19057. [CrossRef] [PubMed]

68. Arciniegas-Grijalba, P.A.; Patiño-Portela, M.C.; Mosquera-Sánchez, L.P.; Guerrero-Vargas, J.A.; Rodríguez-Páez, J.E. ZnO nanoparticles (ZnO-NPs) and their antifungal activity against coffee fungus Erythricium salmonicolor. Appl. Nanosci. 2017, 7, 225-241. [CrossRef]

69. Rana, P.; Abdullah, M.; Hameed, H.Q.; Hasan, A.A. The effect of Olea europea L. leaves extract and $\mathrm{ZrO}_{2}$ nanoparticles on Acinetobacter baumannii. J. Pharm. Sci. Res. 2019, 11, 2019.

70. Joshi, S.M.; De Britto, S.; Jogaiah, S.; Ito, S.I. Mycogenic selenium nanoparticles as potential new generation broad spectrum antifungal molecules. Biomolecules 2019, 9, 419. [CrossRef]

71. Srivastava, N.; Mukhopadhyay, M. Green synthesis and structural characterization of selenium nanoparticles and assessment of their antimicrobial property. Bioprocess Biosyst. Eng. 2015, 38. [CrossRef]

72. Khiralla, G.M.; El-Deeb, B.A. Antimicrobial and antibiofilm effects of selenium nanoparticles on some foodborne pathogens. LWT Food Sci. Technol. 2015, 63, 1001-1007. [CrossRef]

73. Shakibaie, M.; Forootanfar, H.; Golkari, Y.; Mohammadi-Khorsand, T.; Shakibaie, M.R. Anti-biofilm activity of biogenic selenium nanoparticles and selenium dioxide against clinical isolates of Staphylococcus aureus, Pseudomonas aeruginosa, and Proteus mirabilis. J. Trace Elem. Med. Biol. 2015, 29, 235-241. [CrossRef]

74. Abo Elsoud, M.M.; Al-Hagar, O.E.A.; Abdelkhalek, E.S.; Sidkey, N.M. Synthesis and investigations on tellurium myconanoparticles. Biotechnol. Rep. 2018, 18, e00247. [CrossRef] [PubMed]

75. Brown, C.D.; Cruz, D.M.; Roy, A.K.; Webster, T.J. Synthesis and characterization of PVP-coated tellurium nanorods and their antibacterial and anticancer properties. J. Nanopart. Res. 2018, 20, 254. [CrossRef]

76. Siddiqi, K.S.; ur Rahman, A.; Tajuddin; Husen, A. Properties of Zinc Oxide Nanoparticles and Their Activity Against Microbes. Nanoscale Res. Lett. 2018, 13. [CrossRef] [PubMed]

77. Jaffri, S.B.; Ahmad, K.S. Foliar-mediated Ag:ZnO nanophotocatalysts: Green synthesis, characterization, pollutants degradation, and in vitro biocidal activity. Green Process. Synth. 2019, 8, 172-182. [CrossRef]

78. Mohamed, M.A.; Abd-Elsalam, K.A. Nanoantimicrobials for Plant Pathogens Control: Potential Applications and Mechanistic Aspects. In Nanobiotechnology Applications in Plant Protection-Nanotechnology in the Life Sciences; Abd-Elsalam, K.A., Prasad, R., Eds.; Springer International Publishing AG: Cham, Switzerland, 2018; pp. 111-135. ISBN 978-3-319-91160-1.

79. Agarwal, H.; Menon, S.; Venkat Kumar, S.; Rajeshkumar, S. Mechanistic study on antibacterial action of zinc oxide nanoparticles synthesized using green route. Chem. Biol. Interact. 2018, 286, 60-70. [CrossRef]

80. Al-Shabib, N.A.; Husain, F.M.; Ahmed, F.; Khan, R.A.; Ahmad, I.; Alsharaeh, E.; Khan, M.S.; Hussain, A.; Rehman, M.T.; Yusuf, M.; et al. Biogenic synthesis of Zinc oxide nanostructures from Nigella sativa seed: Prospective role as food packaging material inhibiting broad-spectrum quorum sensing and biofilm. Sci. Rep. 2016, 6, 1-16. [CrossRef]

81. Ogunyemi, S.O.; Abdallah, Y.; Zhang, M.; Fouad, H.; Hong, X.; Ibrahim, E.; Masum, M.M.I.; Hossain, A.; Mo, J.; Li, B. Green synthesis of zinc oxide nanoparticles using different plant extracts and their antibacterial activity against Xanthomonas oryzae pv. oryzae. Artif. Cells Nanomed. Biotechnol. 2019, 47, 341-352. [CrossRef]

82. Galié, S.; García-Gutiérrez, C.; Miguélez, E.M.; Villar, C.J.; Lombó, F. Biofilms in the food industry: Health aspects and control methods. Front. Microbiol. 2018, 9, 1-18. [CrossRef] 
83. Kim, S.W.; Kim, K.S.; Lamsal, K.; Kim, Y.J.; Kim, S.B.; Jung, M.; Sim, S.J.; Kim, H.S.; Chang, S.J.; Kim, J.K.; et al. An in vitro study of the antifungal effect of silver nanoparticles on oak wilt pathogen Raffaelea sp. J. Microbiol. Biotechnol. 2009, 19, 760-764. [CrossRef]

84. Lamsal, K.; Kim, S.W.; Jung, J.H.; Kim, Y.S.; Kim, K.S.; Lee, Y.S. Application of silver nanoparticles for the control of Colletotrichum species in vitro and pepper anthracnose disease in field. Mycobiology 2011, 39, 194-199. [CrossRef]

85. Elmer, W.; White, J.C. The Future of Nanotechnology in Plant Pathology. Annu. Rev. Phytopathol. 2018, 56, 111-133. [CrossRef] [PubMed]

86. Park, S.J.; Park, H.H.; Kim, S.Y.; Kim, S.J.; Woo, K.; Ko, G.P. Antiviral properties of silver nanoparticles on a magnetic hybrid colloid. Appl. Environ. Microbiol. 2014, 80, 2343-2350. [CrossRef] [PubMed]

87. Galdiero, S.; Falanga, A.; Vitiello, M.; Cantisani, M.; Marra, V.; Galdiero, M. Silver nanoparticles as potential antiviral agents. Molecules 2011, 16, 8894-8918. [CrossRef]

88. Zeedan, G.S.G.; Abd El-Razik, K.A.; Allam, A.M.; Abdalhamed, A.M.; Abou Zeina, H.A. Evaluations of potential antiviral effects of green zinc oxide and silver nanoparticles against bovine herpesvirus-1. Adv. Anim. Vet. Sci. 2020, 8, 433-443. [CrossRef]

89. Bekele, A.Z.; Gokulan, K.; Williams, K.M.; Khare, S. Dose and Size-Dependent Antiviral Effects of Silver Nanoparticles on Feline Calicivirus, a Human Norovirus Surrogate. Foodborne Pathog. Dis. 2016, 13, 239-244. [CrossRef] [PubMed]

90. Shionoiri, N.; Sato, T.; Fujimori, Y.; Nakayama, T.; Nemoto, M.; Matsunaga, T.; Tanaka, T. Investigation of the antiviral properties of copper iodide nanoparticles against feline calicivirus. J. Biosci. Bioeng. 2012, 113, 580-586. [CrossRef] [PubMed]

91. Kerry, R.G.; Malik, S.; Redda, Y.T.; Sahoo, S.; Patra, J.K.; Majhi, S. Nano-based approach to combat emerging viral (NIPAH virus) infection. Nanomed. Nanotechnol. Biol. Med. 2019, 18, 196-220. [CrossRef]

92. Ben Salem, A.N.; Zyed, R.; Lassoued, M.A.; Nidhal, S.; Sfar, S.; Mahjoub, A. Plant-derived nanoparticles enhance antiviral activity against coxsakievirus B3 by acting on virus particles and vero cells. Dig. J. Nanomater. Biostructs 2012, 7, 737-744.

93. Rai, M.; Deshmukh, S.D.; Ingle, A.P.; Gupta, I.R.; Galdiero, M.; Galdiero, S. Metal nanoparticles: The protective nanoshield against virus infection. Crit. Rev. Microbiol. 2016, 42, 46-56. [CrossRef] [PubMed]

94. Singh, L.; Kruger, H.G.; Maguire, G.E.M.; Govender, T.; Parboosing, R. The role of nanotechnology in the treatment of viral infections. Ther. Adv. Infect. Dis. 2017, 4, 105-131. [CrossRef] [PubMed]

95. Milovanovic, M.; Arsenijevic, A.; Milovanovic, J.; Kanjevac, T.; Arsenijevic, N. Nanoparticles in Antiviral Therapy. Antimicrob. Nanoarchit. Synth. Appl. 2017, 383-410. [CrossRef]

96. Nikaeen, G.; Abbaszadeh, S.; Yousefinejad, S. Application of nanomaterials in treatment, anti-infection and detection of coronaviruses. Nanomedicine 2020. [CrossRef]

97. Itani, R.; Tobaiqy, M.; Al Faraj, A. Optimizing use of theranostic nanoparticles as a life-saving strategy for treating COVID-19 patients. Theranostics 2020, 10, 5932-5942. [CrossRef]

98. Haggag, E.G.; Elshamy, A.M.; Rabeh, M.A.; Gabr, N.M.; Salem, M.; Youssif, K.A.; Samir, A.; Bin Muhsinah, A.; Alsayari, A.; Abdelmohsen, U.R. Antiviral potential of green synthesized silver nanoparticles of Lampranthus coccineus and Malephora lutea. Int. J. Nanomed. 2019, 14, 6217-6229. [CrossRef] [PubMed]

99. Meléndez-Villanueva, M.A.; Morán-Santibañez, K.; Martínez-Sanmiguel, J.J.; Rangel-López, R.; Garza-Navarro, M.A.; Rodríguez-Padilla, C.; Zarate-Triviño, D.G.; Trejo-Ávila, L.M. Virucidal activity of gold nanoparticles synthesized by green chemistry using garlic extract. Viruses 2019, 11, 1111. [CrossRef] [PubMed]

100. Kumar, R.; Sahoo, G.; Pandey, K.; Nayak, M.K.; Topno, R.; Rabidas, V.; Das, P. Virostatic potential of zinc oxide $(\mathrm{ZnO})$ nanoparticles on capsid protein of cytoplasmic side of chikungunya virus. Int. J. Infect. Dis. 2018, 73, 368. [CrossRef]

101. Abdul, W.; Muhammad, A.; Atta Ullah, K.; Asmat, A.; Abdul, B. Role of nanotechnology in diagnosing and treating COVID-19 during the Pandemi. Int. J. Clin. Virol. 2020, 4, 65-70. [CrossRef]

102. El-Dougdoug, N.K.; Bondok, A.M.; El-Dougdoug, K.A. Evaluation of Silver Nanoparticles as Antiviral Agent Against ToMV and PVY in Tomato Plants. Middle East J. Appl. Sci. 2018, 8, 100-111.

103. Shafie, R.M.; Salama, A.M.; Farroh, K.Y. Silver nanoparticles activity against Tomato spotted wilt virus. Middle East J. Appl. Sci. 2018, 7, 1251-1267. 
104. Elbeshehy, E.K.F.; Elazzazy, A.M.; Aggelis, G. Silver nanoparticles synthesis mediated by new isolates of Bacillus spp., nanoparticle characterization and their activity against Bean Yellow Mosaic Virus and human pathogens. Front. Microbiol. 2015, 6, 1-13. [CrossRef]

105. Elazzazy, A.M.; Elbeshehy, E.K.F.; Betiha, M.A. In vitro assessment of activity of graphene silver composite sheets against multidrug-resistant bacteria and Tomato Bushy Stunt Virus. Trop. J. Pharm. Res. 2017, 16, 2705-2711. [CrossRef]

106. Cai, L.; Cai, L.; Jia, H.; Liu, C.; Wang, D.; Sun, X. Foliar exposure of Fe3O4 nanoparticles on Nicotiana benthamiana: Evidence for nanoparticles uptake, plant growth promoter and defense response elicitor against plant virus. J. Hazard. Mater. 2020, 393, 122415. [CrossRef] [PubMed]

107. Hao, Y.; Yuan, W.; Ma, C.; White, J.C.; Zhang, Z.; Adeel, M.; Zhou, T.; Rui, Y.; Xing, B. Engineered nanomaterials suppress Turnip mosaic virus infection in tobacco (Nicotiana benthamiana). Environ. Sci. Nano 2018, 5, 1685-1693. [CrossRef]

108. Hanley, C.; Layne, J.; Punnoose, A.; Reddy, K.M.; Coombs, I.; Coombs, A.; Feris, K.; Wingett, D. Preferential killing of cancer cells and activated human T cells using ZnO nanoparticles. Nanotechnology 2008, 19, 1-7. [CrossRef] [PubMed]

109. Premanathan, M.; Karthikeyan, K.; Jeyasubramanian, K.; Manivannan, G. Selective toxicity of ZnO nanoparticles toward Gram-positive bacteria and cancer cells by apoptosis through lipid peroxidation. Nanomed. Nanotechnol. Biol. Med. 2011, 7, 184-192. [CrossRef] [PubMed]

110. Reddy, K.M.; Feris, K.; Bell, J.; Wingett, D.G.; Hanley, C.; Punnoose, A. Selective toxicity of zinc oxide nanoparticles to prokaryotic and eukaryotic systems. Appl. Phys. Lett. 2007, 90,1-8. [CrossRef]

111. Sirelkhatim, A.; Mahmud, S.; Seeni, A.; Kaus, N.H.M.; Ann, L.C.; Bakhori, S.K.M.; Hasan, H.; Mohamad, D. Review on zinc oxide nanoparticles: Antibacterial activity and toxicity mechanism. Nano-Micro Lett. 2015, 7, 219-242. [CrossRef]

112. Tiwari, V.; Mishra, N.; Gadani, K.; Solanki, P.S.; Shah, N.A.; Tiwari, M. Mechanism of anti-bacterial activity of zinc oxide nanoparticle against Carbapenem-Resistant Acinetobacter baumannii. Front. Microbiol. 2018, 9, 1-10. [CrossRef]

113. Sun, T.; Hao, H.; Hao, W.T.; Yi, S.M.; Li, X.P.; Li, J.R. Preparation and antibacterial properties of titanium-doped ZnO from different zinc salts. Nanoscale Res. Lett. 2014, 9, 1-11. [CrossRef]

114. Jiang, J.; Pi, J.; Cai, J. The Advancing of Zinc Oxide Nanoparticles for Biomedical Applications. Bioinorg. Chem. Appl. 2018, 2018. [CrossRef]

115. Pinto, R.M.; Lopes-De-Campos, D.; Martins, M.C.L.; Van Dijck, P.; Nunes, C.; Reis, S. Impact of nanosystems in Staphylococcus aureus biofilms treatment. FEMS Microbiol. Rev. 2019, 43, 622-641. [CrossRef] [PubMed]

116. Graham, J.H.; Johnson, E.G.; Myers, M.E.; Young, M.; Rajasekaran, P.; Das, S.; Santra, S. Potential of Nano-Formulated Zinc Oxide for Control of Citrus Canker on Grapefruit Trees. Plant Dis. 2016, 100, 2442-2447. [CrossRef] [PubMed]

117. Carvalho, R.; Duman, K.; Jones, J.B.; Paret, M.L. Bactericidal Activity of Copper-Zinc Hybrid Nanoparticles on Copper-Tolerant Xanthomonas perforans. Sci. Rep. 2019, 9, 1-9. [CrossRef] [PubMed]

118. Siddiqui, Z.A.; Khan, A.; Khan, M.R.; Abd-Allah, E.F. Effects of zinc oxide nanoparticles (ZnO NPs) and some plant pathogens on the growth and nodulation of lentil (Lens culinaris medik.). Acta Phytopathol. Entomol. Hungarica 2018, 53, 195-212. [CrossRef]

119. Khan, M.; Siddiqui, Z.A. Zinc oxide nanoparticles for the management of Ralstonia solanacearum, Phomopsis vexans and Meloidogyne incognita incited disease complex of eggplant. Indian Phytopathol. 2018, 71, 355-364. [CrossRef]

120. Alves, M.M.; Bouchami, O.; Tavares, A.; Córdoba, L.; Santos, C.F.; Miragaia, M.; De Fátima Montemor, M. New Insights into Antibiofilm Effect of a Nanosized ZnO Coating against the Pathogenic Methicillin Resistant Staphylococcus aureus. ACS Appl. Mater. Interfaces 2017, 9, 28157-28167. [CrossRef]

121. Fontecha-Umaña, F.; Ríos-Castillo, A.G.; Ripolles-Avila, C.; Rodríguez-Jerez, J.J. Antimicrobial activity and prevention of bacterial biofilm formation of silver and zinc oxide nanoparticle-containing polyester surfaces at various concentrations for use. Foods 2020, 9, 442. [CrossRef]

122. Jindal, S.; Anand, S.; Huang, K.; Goddard, J.; Metzger, L.; Amamcharla, J. Evaluation of modified stainless steel surfaces targeted to reduce biofilm formation by common milk spore formers. J. Dairy Sci. 2016, 99, 9502-9513. [CrossRef] 
123. Espitia, P.J.P.; Otoni, C.G.; Soares, N.F.F. Zinc Oxide Nanoparticles for Food Packaging Applications; Elsevier Inc.: Amsterdam, The Netherlands, 2016; ISBN 9780128007235.

124. Kaur, M.; Kalia, A.; Thakur, A. Effect of biodegradable chitosan-rice-starch nanocomposite films on post-harvest quality of stored peach fruit. Starch/Staerke 2017, 69, 1-12. [CrossRef]

125. Naskar, A.; Khan, H.; Sarkar, R.; Kumar, S.; Halder, D.; Jana, S. Anti-biofilm activity and food packaging application of room temperature solution process-based polyethylene glycol capped Ag-ZnO-graphene nanocomposite. Mater. Sci. Eng. C 2018, 91, 743-753. [CrossRef] [PubMed]

126. Gundersen, D.E.; Lee, I.M.; Rehner, S.A.; Davis, R.E.; Kingsbury, D.T. Phylogeny of mycoplasmalike organisms (phytoplasmas): A basis for their classification. J. Bacteriol. 1994, 176, 5244-5254. [CrossRef] [PubMed]

127. Bové, J.M.; Garnier, M. Walled and wall-less eubacteria from plants: Sieve-tube-restricted plant pathogens. Plant Cell. Tissue Organ Cult. 1998, 52, 7-16. [CrossRef]

128. Lee, I.; Davis, R.E.; Dawn, E. Phytoplasma: Phytopathogenic Mollicutes. Annu. Rev. Microbiol. 2000, 54, 221-255. [CrossRef] [PubMed]

129. Jurga, M.; Zwolińska, A. Phytoplasmas in Poaceae species: A threat to the most important cereal crops in Europe. J. Plant Pathol. 2020, 102, 287-297. [CrossRef]

130. Rao, G.P.; Madhupriya; Thorat, V.; Manimekalai, R.; Tiwari, A.K.; Yadav, A. A century progress of research on phytoplasma diseases in India. Phytopathog. Mollicutes 2017, 7, 1. [CrossRef]

131. Kumari, S.; Nagendran, K.; Rai, A.B.; Singh, B.; Rao, G.P.; Bertaccini, A. Global status of phytoplasma diseases in vegetable crops. Front. Microbiol. 2019, 10,1-15. [CrossRef]

132. Namba, S. Molecular and biological properties of phytoplasmas. Proc. Jpn. Acad. Ser. B Phys. Biol. Sci. 2019, 95, 401-418. [CrossRef]

133. Fletcher, J.; Wayadande, A.; Melcher, U.; Ye, F. The phytopathogenic mollicute-insect vector interface: A closer look. Phytopathology 1998, 88, 1351-1358. [CrossRef]

134. Bendix, C.; Lewis, J.D. The enemy within: Phloem-limited pathogens. Mol. Plant Pathol. 2018, 19, $238-254$. [CrossRef]

135. Cagliari, D.; Dias, N.P.; Galdeano, D.M.; dos Santos, E.Á.; Smagghe, G.; Zotti, M.J. Management of pest insects and plant diseases by non-transformative RNAi. Front. Plant Sci. 2019, 10. [CrossRef]

136. Liu, S.; Jaouannet, M.; Dempsey, D.A.; Imani, J.; Coustau, C.; Kogel, K.H. RNA-based technologies for insect control in plant production. Biotechnol. Adv. 2020, 39, 107463. [CrossRef] [PubMed]

137. Yang, C.; Powell, C.A.; Duan, Y.; Shatters, R.; Zhang, M. Antimicrobial nanoemulsion formulation with improved penetration of foliar spray through citrus leaf cuticles to control citrus huanglongbing. PLoS ONE 2015, 10, 1-14. [CrossRef] [PubMed]

138. Yang, C.; Zhong, Y.; Powell, C.A.; Doud, M.S.; Duan, Y.; Huang, Y.; Zhang, M. Antimicrobial Compounds Effective against Candidatus Liberibacter asiaticus Discovered via Graft-based Assay in Citrus. Sci. Rep. 2018, 8, 1-11. [CrossRef]

139. Gabiel, D.W.; Zhang, S. Use of Aldehydes Formulated with Nanoparticles and/or Nanoemulsions to Enhance Disease Resistance of Plants to Liberibacters. US Patent (US20170006863), 12 January 2017.

140. Ghosh, D.K.; Kokane, S.; Kumar, P.; Ozcan, A.; Warghane, A.; Motghare, M.; Santra, S.; Sharma, A.K. Antimicrobial nano-zinc oxide-2S albumin protein formulation significantly inhibits growth of "Candidatus Liberibacter asiaticus" in planta. PLoS ONE 2018, 13, 1-20. [CrossRef]

141. Wagner, G.; Korenkov, V.; Judy, J.D.; Bertsch, P.M. Nanoparticles composed of Zn and ZnO inhibit Peronospora tabacina spore germination in vitro and P. tabacina infectivity on tobacco leaves. Nanomaterials 2016, 6, 50. [CrossRef]

142. Zabrieski, Z.; Morrell, E.; Hortin, J.; Dimkpa, C.; McLean, J.; Britt, D.; Anderson, A. Pesticidal activity of metal oxide nanoparticles on plant pathogenic isolates of Pythium. Ecotoxicology 2015, 24, 1305-1314. [CrossRef] [PubMed]

143. Patra, P.; Mitra, S.; Debnath, N.; Goswami, A. Biochemical-, biophysical-, and microarray-based antifungal evaluation of the buffer-mediated synthesized nano zinc oxide: An in vivo and in vitro toxicity study. Langmuir 2012, 28, 16966-16978. [CrossRef] [PubMed]

144. He, L.; Liu, Y.; Mustapha, A.; Lin, M. Antifungal activity of zinc oxide nanoparticles against Botrytis cinerea and Penicillium expansum. Microbiol. Res. 2011, 166, 207-215. [CrossRef] [PubMed] 
145. Hassan, M.; Zayton, M.A.; El-feky, S.A. Role of green synthesized ZnO nanoparticles as antifungal against post-harvest gray and black mold of sweet bell. J. Biotechnol. Bioeng. 2019, 3, 8-15.

146. Dimkpa, C.O.; McLean, J.E.; Britt, D.W.; Anderson, A.J. Antifungal activity of ZnO nanoparticles and their interactive effect with a biocontrol bacterium on growth antagonism of the plant pathogen Fusarium graminearum. BioMetals 2013, 26, 913-924. [CrossRef]

147. El-argawy, E.; Rahhal, M.M.H.; Elshabrawy, E.M.; Eltahan, R.M. Efficacy of some nanoparticles to control damping-off and root rot of sugar beet in El-Behiera Governorate. Asian J. Plant Pathol. 2016, 11, 35-47. [CrossRef]

148. Sardella, D.; Gatt, R.; Valdramidis, V.P. Assessing the efficacy of zinc oxide nanoparticles against Penicillium expansum by automated turbidimetric analysis. Mycology 2018, 9, 43-48. [CrossRef] [PubMed]

149. Shoeb, M.; Singh, B.R.; Khan, J.A.; Khan, W.; Singh, B.N.; Singh, H.B.; Naqvi, A.H. ROS-dependent anticandidal activity of zinc oxide nanoparticles synthesized by using egg albumen as a biotemplate. Adv. Nat. Sci. Nanosci. Nanotechnol. 2013, 4. [CrossRef]

150. Horky, P.; Skalickova, S.; Baholet, D.; Skladanka, J. Nanoparticles as a solution for eliminating the risk of mycotoxins. Nanomaterials 2018, 8, 727. [CrossRef]

151. Gacem, M.A.; Gacem, H.; Telli, A.; Ould El Hadj Khelil, A. Mycotoxins: Decontamination and nanocontrol methods. In Nanomycotoxicology: Treating Mycotoxins in the Nano Way; Rai, M., Abd-Elsalam, K.A., Eds.; Elsevier Inc.: Amsterdam, The Netherlands, 2020; pp. 189-216. ISBN 9780128179987.

152. Tsang, C.C.; Tang, J.Y.M.; Lau, S.K.P.; Woo, P.C.Y. Taxonomy and evolution of Aspergillus, Penicillium and Talaromyces in the omics era-Past, present and future. Comput. Struct. Biotechnol. J. 2018, 16, 197-210. [CrossRef] [PubMed]

153. El-banna, A.A.; Pitt, J.I.; Leistner, L. Production of mycotoxins by Penicillium species. Syst. Appl. Microbiol. 1987, 10, 42-46. [CrossRef]

154. Frisvad, J.C. A critical review of producers of small lactone mycotoxins: Patulin, penicillic acid and moniliformin. World Mycotoxin J. 2018, 11, 73-100. [CrossRef]

155. Jimenez-Garcia, S.N.; Garcia-Mier, L.; Garcia-Trejo, J.F.; Ramirez-Gomez, X.S.; Guevara-Gonzalez, R.G.; Feregrino-Perez, A.A. Fusarium mycotoxins and metabolites that modulate their production. In Fusarium - Plant Diseases, Pathogen Diversity, Genetic Diversity, Resistance and Molecular Markers; InTech: London, UK, 2018. [CrossRef]

156. Hulvová, H.; Galuszka, P.; Frébortová, J.; Frébort, I. Parasitic fungus Claviceps as a source for biotechnological production of ergot alkaloids. Biotechnol. Adv. 2013, 31, 79-89. [CrossRef]

157. Bennett, J.W.; Klich, M. Mycotoxins. Clin. Microbiol. Rev. 2003, 16, 497-516. [CrossRef]

158. Schardl, C.L. Introduction to the toxins special issue on ergot alkaloids. Toxins 2015, 7, 4232-4237. [CrossRef]

159. Ostry, V. Alternaria mycotoxins: An overview of chemical characterization, producers, toxicity, analysis and occurrence in foodstuffs. World Mycotoxin J. 2008, 1, 175-188. [CrossRef]

160. Jesmin, R.; Chanda, A. Restricting mycotoxins without killing the producers: A new paradigm in nano-fungal interactions. Appl. Microbiol. Biotechnol. 2020, 104, 2803-2813. [CrossRef] [PubMed]

161. Kaur, A.; Saini, S.S. Nanoadsorbents for the preconcentration of some toxic substances: A minireview. Int. Lett. Chem. Phys. Astron. 2013, 21, 22-35. [CrossRef]

162. Zahoor, M.; Ali Khan, F. Adsorption of aflatoxin B1 on magnetic carbon nanocomposites prepared from bagasse. Arab. J. Chem. 2018, 11, 729-738. [CrossRef]

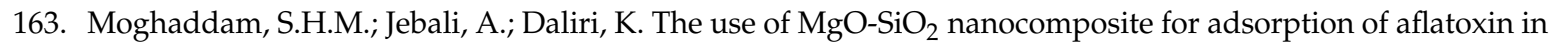
wheat flour samples. In Proceedings of the NanoCon 2010, Olomouc, Czech Republic, 12-14 October 2010; pp. 10-15.

164. Daković, A.; Tomašević-Čanović, M.; Dondur, V.; Rottinghaus, G.E.; Medaković, V.; Zarić, S. Adsorption of mycotoxins by organozeolites. Colloids Surf. B Biointerfaces 2005, 46, 20-25. [CrossRef]

165. Kovač, T.; Borišev, I.; Crevar, B.; Čačić Kenjerić, F.; Kovač, M.; Strelec, I.; Ezekiel, C.N.; Sulyok, M.; Krska, R.; Šarkanj, B. Fullerol C60(OH)24 nanoparticles modulate aflatoxin B1 biosynthesis in Aspergillus flavus. Sci. Rep. 2018, 8, 1-8. [CrossRef]

166. Asghar, M.A.; Zahir, E.; Shahid, S.M.; Khan, M.N.; Asghar, M.A.; Iqbal, J.; Walker, G. Iron, copper and silver nanoparticles: Green synthesis using green and black tea leaves extracts and evaluation of antibacterial, antifungal and aflatoxin B1 adsorption activity. LWT Food Sci. Technol. 2018, 90, 98-107. [CrossRef] 
167. Hernández-Meléndez, D.; Salas-Téllez, E.; Zavala-Franco, A.; Téllez, G.; Méndez-Albores, A.; Vázquez-Durán, A. Inhibitory effect of flower-shaped zinc oxide nanostructures on the growth and aflatoxin production of a highly toxigenic strain of Aspergillus flavus Link. Materials 2018, 11, 1265. [CrossRef]

168. Mitra, C.; Gummadidala, P.M.; Merrifield, R.; Omebeyinje, M.H.; Jesmin, R.; Lead, J.R.; Chanda, A. Size and coating of engineered silver nanoparticles determine their ability to growth-independently inhibit aflatoxin biosynthesis in Aspergillus parasiticus. Appl. Microbiol. Biotechnol. 2019, 103, 4623-4632. [CrossRef]

169. Mitra, C.; Gummadidala, P.M.; Afshinnia, K.; Merrifield, R.C.; Baalousha, M.; Lead, J.R.; Chanda, A. Citrate-Coated Silver Nanoparticles Growth-Independently Inhibit Aflatoxin Synthesis in Aspergillus parasiticus. Environ. Sci. Technol. 2017, 51, 8085-8093. [CrossRef]

170. Lakshmeesha, T.R.; Kalagatur, N.K.; Mudili, V.; Mohan, C.D.; Rangappa, S.; Prasad, B.D.; Ashwini, B.S.; Hashem, A.; Alqarawi, A.A.; Malik, J.A.; et al. Biofabrication of zinc oxide nanoparticles with Syzygium aromaticum flower buds extract and finding its novel application in controlling the growth and mycotoxins of Fusarium graminearum. Front. Microbiol. 2019, 10, 1-13. [CrossRef] [PubMed]

171. Mohd Yusof, H.; Mohamad, R.; Zaidan, U.H.; Abdul Rahman, N.A. Microbial synthesis of zinc oxide nanoparticles and their potential application as an antimicrobial agent and a feed supplement in animal industry: A review. J. Anim. Sci. Biotechnol. 2019, 10, 1-22. [CrossRef] [PubMed]

172. Jabar, A.K.; Aldhahi, H.H.K.; Salim, H.A. Effect of manufactured iron oxides in control of tomato yellow leaf curl virus (TYLCV). Plant Arch. 2020, 20, 2131-2134.

173. Savi, G.D.; Bortoluzzi, A.J.; Scussel, V.M. Antifungal properties of Zinc-compounds against toxigenic fungi and mycotoxin. Int. J. Food Sci. Technol. 2013, 48, 1834-1840. [CrossRef]

174. Anderson, A.J.; McLean, J.E.; Jacobson, A.R.; Britt, D.W. CuO and ZnO nanoparticles modify interkingdom cell signaling processes relevant to crop production. J. Agric. Food Chem. 2018, 66, 6513-6524. [CrossRef]

175. Liang, Y.; Duan, Y.; Fan, C.; Dong, H.; Yang, J.; Tang, J.; Tang, G.; Wang, W.; Jiang, N.; Cao, Y. Preparation of kasugamycin conjugation based on $\mathrm{ZnO}$ quantum dots for improving its effective utilization. Chem. Eng. J. 2019, 361, 671-679. [CrossRef]

176. Young, M.; Ozcan, A.; Myers, M.E.; Johnson, E.G.; Graham, J.H.; Santra, S. Multimodal generally recognized as safe $\mathrm{ZnO} /$ Nanocopper composite: A novel antimicrobial material for the management of citrus phytopathogens. J. Agric. Food Chem. 2018, 66, 6604-6608. [CrossRef]

177. Lahuf, A.A.; Kareem, A.A.; Al-Sweedi, T.M.; Alfarttoosi, H.A. Evaluation the potential of indigenous biocontrol agent Trichoderma harzianum and its interactive effect with nanosized $\mathrm{ZnO}$ particles against the sunflower damping-off pathogen, Rhizoctonia solani. In IOP Conference Series: Earth and Environmental Science; IOP Publishing: Bristol, UK, 2019; Volume 365. [CrossRef]

178. Li, Z.; Yu, T.; Paul, R.; Fan, J.; Yang, Y.; Wei, Q. Agricultural nanodiagnostics for plant diseases: Recent advances and challenges. Nanoscale Adv. 2020. [CrossRef]

179. Khiyami, M.A.; Almoammar, H.; Awad, Y.M.; Alghuthaymi, M.A. Plant pathogen nanodiagnostic techniques: Forthcoming changes? Biotechnol. Biotechnol. Equip. 2014, 28, 775-785. [CrossRef]

180. Giraldo, J.P.; Wu, H.; Newkirk, G.M.; Kruss, S. Nanobiotechnology approaches for engineering smart plant sensors. Nat. Nanotechnol. 2019, 14, 541-553. [CrossRef]

181. Kumar, V.; Arora, K. Trends in nano-inspired biosensors for plants. Mater. Sci. Energy Technol. 2020, 3, 255-273. [CrossRef]

182. Ansari, A.A.; Kaushik, A.; Solanki, P.R.; Malhotra, B.D. Nanostructured zinc oxide platform for mycotoxin detection. Bioelectrochemistry 2010, 77, 75-81. [CrossRef] [PubMed]

183. Martynenko, I.V.; Litvin, A.P.; Purcell-Milton, F.; Baranov, A.V.; Fedorov, A.V.; Gun'Ko, Y.K. Application of semiconductor quantum dots in bioimaging and biosensing. J. Mater. Chem. B 2017, 5, 6701-6727. [CrossRef]

184. Willard, D.M.; Carillo, L.L.; Jung, J.; van Orden, A. CdSe-ZnS Quantum Dots as Resonance Energy Transfer Donors in a Model Protein-Protein Binding Assay. Nano Lett. 2001, 1, 469-474. [CrossRef]

185. Chen, F.; Gerion, D. Fluorescent CdSe/ZnS nanocrystal-peptide conjugates for long-term, nontoxic imaging and nuclear targeting in living cells. Nano Lett. 2004, 4, 1827-1832. [CrossRef]

186. Hong, S.; Lee, C. The current status and future outlook of quantum dot-based biosensors for plant virus detection. Plant Pathol. J. 2018, 34, 85-92. [CrossRef]

187. Medintz, I.L.; Sapsford, K.E.; Konnert, J.H.; Chatterji, A.; Lin, T.; Johnson, J.E.; Mattoussi, H. Decoration of discretely immobilized cowpea mosaic virus with luminescent quantum dots. Langmuir 2005, 21, 5501-5510. [CrossRef] 
188. Moulick, A.; Milosavljevic, V.; Vlachova, J.; Podgajny, R.; Hynek, D.; Kopel, P.; Adam, V. Using CdTe/ZnSe core/shell quantum dots to detect DNA and damage to DNA. Int. J. Nanomed. 2017, 12, 1277-1291. [CrossRef]

189. Rispail, N.; De Matteis, L.; Santos, R.; Miguel, A.S.; Custardoy, L.; Testillano, P.S.; Risueño, M.C.; Pérez-De-Luque, A.; Maycock, C.; Fevereiro, P.; et al. Quantum dot and superparamagnetic nanoparticle interaction with pathogenic fungi: Internalization and toxicity profile. ACS Appl. Mater. Interfaces 2014, 6, 9100-9110. [CrossRef]

190. Tereshchenko, A.; Fedorenko, V.; Smyntyna, V.; Konup, I.; Konup, A.; Eriksson, M.; Yakimova, R.; Ramanavicius, A.; Balme, S.; Bechelany, M. ZnO films formed by atomic layer deposition as an optical biosensor platform for the detection of Grapevine virus A-type proteins. Biosens. Bioelectron. 2017, 92, 763-769. [CrossRef]

191. Al-Fandi, M.G.; Alshraiedeh, N.H.; Oweis, R.J.; Hayajneh, R.H.; Alhamdan, I.R.; Alabed, R.A.; Al-Rawi, O.F. Direct electrochemical bacterial sensor using $\mathrm{ZnO}$ nanorods disposable electrode. Sens. Rev. 2018, 38, 326-334. [CrossRef]

192. Tahir, M.A.; Hameed, S.; Munawar, A.; Amin, I.; Mansoor, S.; Khan, W.S.; Bajwa, S.Z. Investigating the potential of multiwalled carbon nanotubes based zinc nanocomposite as a recognition interface towards plant pathogen detection. J. Virol. Methods 2017, 249, 130-136. [CrossRef] [PubMed]

193. Siddiquee, S.; Rovina, K.; Yusof, N.A.; Rodrigues, K.F.; Suryani, S. Nanoparticle-enhanced electrochemical biosensor with DNA immobilization and hybridization of Trichoderma harzianum gene. Sens. Bio-Sens. Res. 2014, 2, 16-22. [CrossRef]

194. Kalia, A.; Kaur, H. Agri-Applications of Nano-Scale Micronutrients: Prospects for Plant Growth Promotion; Raliya, R., Ed.; CRC Press: Boca Raton, FL, USA, 2019; ISBN 9781315123950.

195. Bala, R.; Kalia, A.; Dhaliwal, S.S. Evaluation of Efficacy of ZnO Nanoparticles as Remedial Zinc Nanofertilizer for Rice. J. Soil Sci. Plant Nutr. 2019, 19, 379-389. [CrossRef]

196. Kalia, A.; Sharma, S.P.; Kaur, H.; Kaur, H. Novel nanocomposite-based controlled-release fertilizer and pesticide formulations: Prospects and challenges. In Multifunctional Hybrid Nanomaterials for Sustainable Agri-food and Ecosystem; Abd-Elsalam, K.A., Ed.; Elsevier Inc.: Amsterdam, The Netherlands, 2020; pp. 99-134.

197. Kalia, A.; Sharma, S.P.; Kaur, H. Nanoscale Fertilizers: Harnessing Boons for Enhanced Nutrient Use Efficiency and Crop Productivity. In Nanotechnology in the Life Sciences; Abd-Elsalam, K.A., Prasad, R., Eds.; Springer International Publishing: Cham, Switzerland, 2019; ISBN 978-3-030-13295-8.

198. Kairyte, K.; Kadys, A.; Luksiene, Z. Antibacterial and antifungal activity of photoactivated ZnO nanoparticles in suspension. J. Photochem. Photobiol. B Biol. 2013, 128, 78-84. [CrossRef] [PubMed]

199. Sun, Q.; Li, J.; Le, T. Zinc Oxide Nanoparticle as a Novel Class of Antifungal Agents: Current Advances and Future Perspectives. J. Agric. Food Chem. 2018, 66, 11209-11220. [CrossRef] [PubMed]

200. Jameel, M.; Shoeb, M.; Khan, M.T.; Ullah, R.; Mobin, M.; Farooqi, M.K.; Adnan, S.M. Enhanced Insecticidal Activity of Thiamethoxam by Zinc Oxide Nanoparticles: A Novel Nanotechnology Approach for Pest Control. ACS Omega 2019. [CrossRef]

201. Medina-Pérez, G.; Fernández-Luqueño, F.; Vazquez-Nuñez, E.; López-Valdez, F.; Prieto-Mendez, J.; Madariaga-Navarrete, A.; Miranda-Arámbula, M. Remediating Polluted Soils Using Nanotechnologies: Environmental Benefits and Risks. Polish J. Environ. Stud. 2019, 28, 1013-1030. [CrossRef]

202. Das, S.; Chakraborty, J.; Chatterjee, S.; Kumar, H. Prospects of biosynthesized nanomaterials for the remediation of organic and inorganic environmental contaminants. Environ. Sci. Nano 2018, 5, 2784-2808. [CrossRef]

203. Guerra, F.; Attia, M.; Whitehead, D.; Alexis, F. Nanotechnology for Environmental Remediation: Materials and Applications. Molecules 2018, 23, 1760. [CrossRef]

204. Fu, L.; Wang, Z.; Dhankher, O.P.; Xing, B. Nanotechnology as a new sustainable approach for controlling crop diseases and increasing agricultural production. J. Exp. Bot. 2020, 71, 507-519. [PubMed]

205. Kookana, R.S.; Boxall, A.B.A.; Reeves, P.T.; Ashauer, R.; Beulke, S.; Chaudhry, Q.; Cornelis, G.; Fernandes, T.F.; Gan, J.; Kah, M.; et al. Nanopesticides: Guiding principles for regulatory evaluation of environmental risks. J. Agric. Food Chem. 2014, 62, 4227-4240. [CrossRef] [PubMed]

206. Walker, G.W.; Kookana, R.S.; Smith, N.E.; Kah, M.; Doolette, C.L.; Reeves, P.T.; Lovell, W.; Anderson, D.J.; Turney, T.W.; Navarro, D.A. Ecological risk assessment of nano-enabled pesticides: A perspective on problem formulation. J. Agric. Food Chem. 2017. [CrossRef] [PubMed] 
207. Kah, M.; Tufenkji, N.; White, J.C. Nano-enabled strategies to enhance crop nutrition and protection. Nat. Nanotechnol. 2019, 14, 532-540. [CrossRef]

208. Beegam, A.; Prasad, P.; Jose, J.; Oliveira, M.; Costa, F.G.; Soares, A.M.V.M.; Gonçalves, P.P.; Trindade, T.; Kalarikkal, N.; Thomas, S.; et al. Environmental Fate of Zinc Oxide Nanoparticles: Risks and Benefits. In Toxicology-New Aspects to This Scientific Conundrum; Soloneski, S., Larramendy, M.L., Eds.; IntechOpen: London, UK, 2016. [CrossRef]

209. Charitidis, C.A.; Georgiou, P.; Koklioti, M.A.; Trompeta, A.F.; Markakis, V. Manufacturing nanomaterials: From research to industry. Manuf. Rev. 2014, 1, 11. [CrossRef]

210. Kalia, A.; Singh, S. Myco-decontamination of azo dyes: Nano-augmentation technologies. 3 Biotech 2020, 10, 384. [CrossRef]

211. Kaur, P.; Taggar, M.S.; Kalia, A. Characterization of magnetic nanoparticle-immobilized cellulases for enzymatic saccharification of rice straw. Biomass Convers. Biorefinery 2020. [CrossRef]

212. Huang, Y.; Ding, L.; Li, C.; Wu, M.; Wang, M.; Yao, C.; Yin, X.; Zhang, J.; Liu, J.; Zhang, Y.; et al. Safety Issue of Changed Nanotoxicity of Zinc Oxide Nanoparticles in the Multicomponent System. Part. Part. Syst. Charact. 2019, 36, 1-14. [CrossRef]

213. Nel, A.; Grainger, D.; Alvarez, P.J.; Badesha, S.; Castranova, V.; Ferrari, M.; Godwin, H.; Grodzinski, P.; Morris, J.; Savage, N.; et al. Nanotechnology Environmental, Health, and Safety Issues. In Nanotechnology Research Directions for Societal Needs in 2020; Roco, M.C., Hersam, M.C., Mirkin, C.A., Eds.; Springer: Dordrecht, The Netherlands, 2011; pp. 159-220. ISBN 9789400711686.

214. Ali, A.; Phull, A.R.; Zia, M. Elemental zinc to zinc nanoparticles: Is ZnO NPs crucial for life? Synthesis, toxicological, and environmental concerns. Nanotechnol. Rev. 2018, 7, 413-441. [CrossRef]

215. Paul, S.K.; Dutta, H.; Sarkar, S.; Sethi, L.N.; Ghosh, S.K. Nanosized Zinc Oxide: Super-functionalities, present scenario of application, safety issues, and future prospects in food processing and allied industries. Food Rev. Int. 2019, 35, 505-535. [CrossRef]

216. Naveed Ul Haq, A.; Nadhman, A.; Ullah, I.; Mustafa, G.; Yasinzai, M.; Khan, I. Synthesis Approaches of Zinc Oxide Nanoparticles: The Dilemma of Ecotoxicity. J. Nanomater. 2017, 2017, 1-14. [CrossRef]

217. Haque, J.; Bellah, M.; Hassan, R.; Rahman, S. Synthesis of ZnO nanoparticles by two different methods and comparison of their structural, antibacterial, photocatalytic and optical properties. Nano Express 2020, 1, 010007. [CrossRef]

218. Marsalek, R. Particle size and Zeta Potential of ZnO. Procedia-Soc. Behav. Sci. 2014, 9, 13-17. [CrossRef]

219. Chai, M.H.H.; Amir, N.; Yahya, N.; Saaid, I.M. Characterization and Colloidal Stability of Surface Modified Zinc Oxide Nanoparticle Characterization and Colloidal Stability of Surface Modified Zinc Oxide Nanoparticle. IOP Conf. Ser. J. Phys. Conf. Ser. 2018, 1123. [CrossRef]

220. Zhulina, E.B.; Borisov, O.V.; Priamitsyn, V.A. Theory of steric stabilization of colloid dispersions by grafted polymers. J. Colloid Interface Sci. 1990, 137, 495-511. [CrossRef]

221. Fiedot, M.; Rac, O.; Suchorska-Woźniak, P.; Karbownik, I.; Teterycz, H. Polymer-surfactant interactions and their influence on zinc oxide nanoparticles morphology. In Manufacturing Nanostructures; Ahmad, W., Ali, N., Eds.; One Central Press: Manchester, UK, 2014; pp. 108-128.

222. Meibner, T.; Oelschlagel, K.; Potthoff, A. Implications of the stability behavior of zinc oxide nanoparticles for toxicological studies. Int. Nano Lett. 2014, 4, 116. [CrossRef]

223. Hsiao, I.; Huang, Y. Effects of various physicochemical characteristics on the toxicities of $\mathrm{ZnO}$ and $\mathrm{TiO}_{2}$ nanoparticles toward human lung epithelial cells. Sci. Total Environ. 2011, 409, 1219-1228. [CrossRef]

(C) 2020 by the authors. Licensee MDPI, Basel, Switzerland. This article is an open access article distributed under the terms and conditions of the Creative Commons Attribution (CC BY) license (http://creativecommons.org/licenses/by/4.0/). 